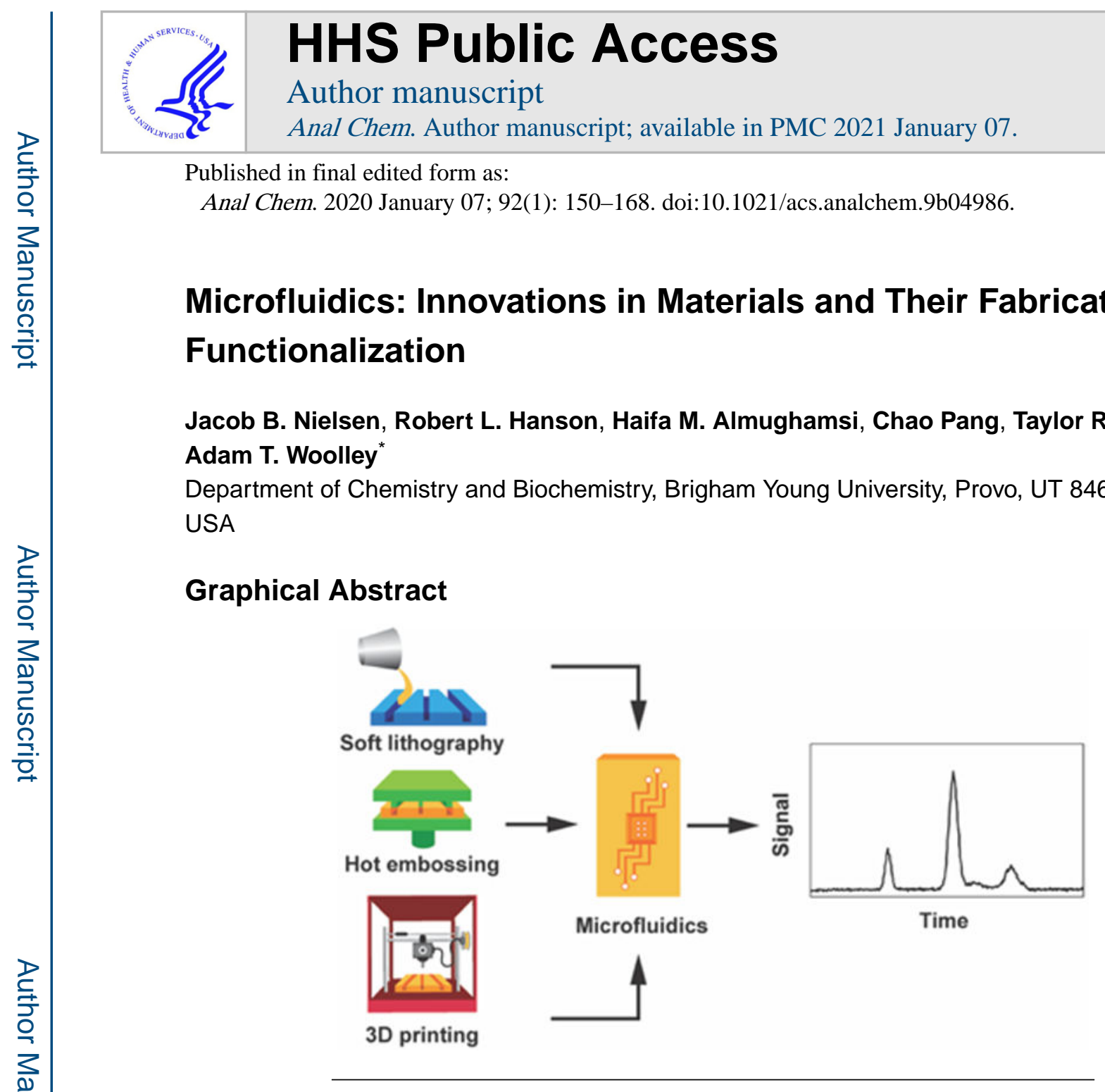

\title{
INTRODUCTION
}

Microfluidics is a growing field of study because these devices offer novel and versatile approaches for addressing a range of scientific problems. Microfluidics have been used in separations, ${ }^{1}$ cell analysis, ${ }^{2,3}$ and microreactors, ${ }^{4}$ to illustrate a few applications.

Microfluidics have been defined in terms of microliter volumes or micrometer dimensions of channels. For this review, we utilize the latter definition, where microfluidic channels range from 1-1000 $\mu \mathrm{m}$ in width or height. Microfluidic devices are fabricated in a host of ways, with a large variety of materials. Indeed, device material can affect flow, absorptivity, biocompatibility, and function of microfluidic components.

Common materials for microfluidics include rigid polymers, polydimethylsiloxane (PDMS), inorganics such as glass or $\mathrm{Si}$, paper, and combinations of these materials, including ones made by 3D printing (3DP). Thermoplastics and PDMS are widely used, because they are relatively inexpensive and well researched. ${ }^{5}$ Paper microfluidics have extremely low cost

"Corresponding Author: Professor Adam T. Woolley; atw @ byu.edu.

One of the authors (ATW) owns shares in Acrea 3D, a company that is commercializing microfluidic 3D printing. 
and can be used to measure desired molecules quickly by visual inspection. ${ }^{6-9} 3 \mathrm{DP}$ is a relatively new approach to fabrication, and many 3DP methods have been successful in forming fluidic channels including fused deposition modeling (FDM), PolyJet (PJ), stereolithography (SLA), and more. ${ }^{10-12}$

In this review, we describe recent advances in microfluidics with a focus on materials, and their fabrication and functionalization methods. The literature cited in this review is largely from work published between July 2017 and July 2019. We discuss inorganic materials (glass, silicon, and ceramics), rigid polymers, PDMS, multicomponent materials, and materials made by 3DP. Paper microfluidics are not covered here, because they have recently been reviewed in this journal. ${ }^{9}$ For each material discussed we describe both device fabrication and applications.

\section{INORGANIC MATERIALS}

The basic techniques of traditional microfabrication include photolithography, wet/dry etching, and additive methods, all of which evolved from microelectromechanical system process technology in the semiconductor industry. ${ }^{13-15}$ Therefore, silicon was the first material to be used for microfluidics because of its thoroughly characterized material and surface properties. ${ }^{16}$ However, many additional factors affect which material is selected for microfluidic device fabrication including solvent compatibility, photochemical properties, chemical resistance, etc. ${ }^{17}$ The manufacturing of first-generation microfluidic chips involved silicon, but glass was soon adopted as well because of stable electroosmotic flow, optical characteristics, and resistance to organic solvents. ${ }^{17}$

Glass has excellent optical transparency and can be compatible with biological samples, so glass microfluidics are widely used for biochemical analysis. However, the fabrication of silicon and glass can be expensive because cleanroom environments with sophisticated instruments are typically required, and suitable protective equipment is also needed for the use of required hazardous chemicals like HF. Additionally, the bonding of etched devices to form microfluidic features typically involves the use of high temperature or pressure. Moreover, it can be challenging to integrate active fluid control into silicon or glass devices, and enclosed channels have poor gas permeability, hindering their use in long-term cell culture. ${ }^{18}$ Although limitations remain for fabrication of silicon and glass microfluidics, they still find use in a number of applications.

\section{Silicon}

The semiconducting properties of Si have made it the dominant material in microfabrication for decades. Extensively characterized surface modification properties based on the silanol group $(-\mathrm{Si}-\mathrm{OH})$, along with chemical resistance and flexibility in design, make silicon a desirable material for creating microfluidic devices. However, the high elastic modulus of silicon (150 GPa) complicates the incorporation of active components such as valves and pumps. ${ }^{19,20}$ Furthermore, silicon devices are not transparent to visible light, which makes them unsuitable for mainstream fluorescence-based detection or direct fluid imaging. To address this issue, transparent materials like glass or polymers are often used to enclose silicon microchannels. ${ }^{17}$ Because the cost is high for making a single microfluidic device 
wafer, multiple devices are often placed on an individual silicon wafer in a batch fabrication process to make it cost effective. As an example, Qi et al. ${ }^{21}$ presented a strategy to reduce the cost per chip by decreasing the size of each chip and doing whole-chip manifold fabrication to get more devices from a single silicon wafer. This fabrication method maintained the same level of precision, robustness, and optical clarity as for larger batch fabrication.

Silicon microfluidic devices have been employed often in biological applications. Li et al. ${ }^{22}$ designed a silicon digital PCR chip that contained millions of reaction wells with a few micron gap between them. This novel chip design, along with a fluorescence imaging method that provided automated image acquisition and stitching, allowed absolute quantitative digital PCR analysis. Because the fluorescence intensity of both amplified and non-PCR amplified DNA was measured, this integrated system could be optimized by eliminating wells with poor performing detection, either during chip fabrication or data processing. Pham et al. ${ }^{23}$ integrated self-assembled fluorescent microbeads and biological receptors into a silicon microfluidic device which was designed to accommodate solutions for immunogold silver staining. This microfluidic system enabled silver staining immunoassays with optical detection to measure the light absorption by the formed silver film on the microbead surface with captured antibodies. This approach offered performance comparable to ELISA, but investigation of reagent shelf life and stability will need to be done.

Silicon-based microfluidic devices are also employed in cell analysis due to precisely fabricated structures. Yin et al. ${ }^{24}$ developed a pyramidal microcavity array with an integrated filter that was capable of $>80 \%$ capture efficiency for circulating tumor cells in whole blood samples, while also preventing pass through of blood cells. Future work involving much larger patient sample sizes would demonstrate the clinical readiness of this approach.

Si plasmonic microarrays were created and used for label-free detection. Ozkumur et al. ${ }^{25}$ utilized Si microfabrication to prepare sensor modules for interferometric detection of unlabeled viral particles. This approach provided a disposable sensor component, but the label-free detection instrumentation was still relatively costly.

An important application of silicon microfluidic devices is in point-of-care medical diagnostics. Migliozzi et al. ${ }^{26}$ created a silicon microfluidic chip with fast delivery of reagents to realize immunostaining and coupled it with fluorescence microscopy and imagebased cell segmentation to obtain fluorescent cell-by-cell images for biomarker quantitation in HER2-type breast carcinoma. Their method provided automated detection and high reproducibility, but was only designed to work with formalin-fixed slides. Garcia-Cordero et al. ${ }^{27}$ developed a system that heterogeneously integrated a sensor with biocompatible microfluidics on a silicon chip to make a platform that collected small volumes of sweat and probed for specific biomarkers. This system allowed for continuous monitoring of sweat $\mathrm{pH}$, and $\mathrm{Na}^{+}$and $\mathrm{K}^{+}$concentrations, but took 20 min to complete a full analysis, so shorter analysis time would be desirable. 
Finally, silicon-based microfluidic devices can be used in organ-on-chip applications for drug toxicity screening. Delalat et al. ${ }^{28}$ developed a surface-modified microfluidic silicon chip as a 3D artificial liver. Micro-trenches on the device surface mimicked the function of the liver sinusoid to provide nutrient transport and waste product removal. This system supported long-term hepatocyte culture and in vitro drug toxicity screening; expanding beyond the three hepatotoxins tested would increase the utility of this platform.

\section{Glass}

Glass has excellent detection performance due to its optical transparency, low fluorescence background, surface stability, chemical resistance, and biological compatibility. Firstgeneration glass microfluidic devices had microchannels, flow reactors, and capillaries for chromatography or electrophoresis. ${ }^{18}$ However, glass fabrication processes are generally complex. For instance, high temperature is typically required during bonding, so glass devices suffer from complications in preloading reagents before assembly. Glass microfluidic devices with standard designs can be obtained commercially from MicroLab Devices, Microflexis, and Schott, as a few examples.

Glass microfluidics allow for experiments under high pressure. Heiland et al. ${ }^{29}$ integrated a pressure- and temperature-controllable glass microfluidic chip platform with supercriticalfluid chromatography to efficiently and rapidly separate chiral and achiral compounds, as a step toward portable chromatography. This system could be beneficial for pharmaceutical or food analysis. Gerhardt et al. ${ }^{30}$ fabricated a pressure-tolerant droplet microfluidic glass chip combined with gradient elution reverse phase chromatography as an approach for preventing peak dispersion. However, placing analyte into discrete droplets slowed the overall separation time several fold. Jonker et al. ${ }^{31}$ developed an approach to test the fracture pressure of two types of commercial glass microfluidic chips (Schott) with different geometries and surface roughness. They found a significant difference in fracture pressure between the two types of chips because of the powder blasting process and HF etching, showing that fabrication methods and designs can affect performance.

Glass chips have been used for microchip electrophoresis $(\mu \mathrm{CE})$ for decades due to electrically insulating and optically transparent properties. ${ }^{32}$ Pinheiro et al. ${ }^{33}$ carried out $\mu \mathrm{CE}$ of inorganic anions present in explosive residues with commercial glass microchips and contactless conductivity detection; however, the limit of detection of $2.5 \mu \mathrm{M}$ was relatively high. Moreira et al. ${ }^{34}$ developed an approach for the separation and detection of illicit drugs by using commercial glass $\mu \mathrm{CE}$ devices that contained two pairs of integrated sensing electrodes for contactless conductivity detection. This method has promise for on-site forensic investigation, provided analyte concentrations are $>40 \mu \mathrm{M}$.

Femtosecond lasers can create complex, 3D microfluidic features in glass. Italia et al. ${ }^{35}$ developed a double Y-shaped glass microfluidic chip with 3D channels using femtosecond laser wet etching. The device diffused two components between adjacent solutions using parallel laminar flows. For best results, the chip design needed a maximum angle of $30^{\circ}$ between the two inlet streams; application beyond simple diffusion of laser dyes is still needed. Shan et al. ${ }^{36}$ utilized femtosecond laser wet etch fabrication to manufacture a 3D helical mixer in a fused silica microfluidic device. Mixing efficiency was tested using a pH 
indicator; if the mixing performance is similarly acceptable for larger molecular weight biological samples, this approach might see broader application. Calmo et al. ${ }^{37}$ combined a microfluidic channel and suspended microchannel resonators in a glass chip, fabricated with femtosecond laser wet etching, for counting bacteria by analyzing liquid density. This system could be expanded in scope of applications to other similar-sized analytes like organelles.

In addition, glass can be used for active components such as pumps and valves. Kazoe et al. 38 created nanofluidic glass devices having a femtoliter chamber with a valve linked to the nanochannels. The open/close function of the valve was realized by deformation of glass. This is a significant technical accomplishment, but it will require further development if the method is to be used in other rigid materials like thermoplastics.

Glass can be used as a material in additive manufacturing of microdevices. Gal-Or et al. ${ }^{39}$ 3D printed devices using molten soda-lime glass in less than an hour as shown in Figure 1. Devices were used as microreactors for linezolid synthesis; additionally, they performed inline Raman spectroscopy, which confirmed the optical quality of the glass structures formed. Kopparthy and Crews ${ }^{40}$ reported a method for making $5 \mathrm{~mm}$ cross-section rectangular or circular channels inside a glass fluidic device using hobby-grade kiln ceramic paper, softened in a conventional household microwave. The whole process of microchannel formation and layer bonding was achieved in one step within $2 \mathrm{~min}$. To get smoother channel walls, further chemical etching was required, which increased channel dimensions. Although promising for its simplicity, this method did not produce channels with microfluidic dimensions, and applications would need to be demonstrated.

Glass can be used as a biocompatible material, which makes it suitable for cell analysis. Hirama et al. ${ }^{41}$ developed a glass-based organ-on-chip microfluidic device for cell-based assays in drug toxicity testing. Compared to PDMS, the glass device didn't absorb hydrophobic molecules and enhanced cell adhesiveness, but oxygen transport could be an issue for longer-time experiments.

\section{Ceramics}

Low temperature co-fired ceramic is an aluminum oxide-based material, which can be fabricated into fluidic platforms, resulting in unique surface chemistry and physical properties. ${ }^{42}$ The multilayer fabrication approach allows the formation of complex fluidic channels.

Berenguel-Alonso et al. ${ }^{43}$ created a low temperature co-fired ceramic microreactor with fluidic channels, a heater, and a detection window for fluorescence imaging. They used the device for production of carbon dots which could be used as nanoprobes for biological diagnosis and heavy metal detection. This material works well in microreactor applications, but its optical properties complicate development of visible wavelength detection strategies. Lantada et al. ${ }^{44}$ developed a ceramic microsystem utilizing lithography-based ceramic manufacturing, where devices had chambers separated by microporous membranes to allow nutrients to permeate. This design could be used for organ-on-chip applications, although 
lithography-based ceramic manufacturing would need further development to allow broader usage in microfluidics.

Inorganic material microfluidics are not ideally suited for prototyping experiments, but nonetheless have valuable areas of application where select properties can be leveraged. Thus, when high temperatures or pressures are needed, inorganic materials are desirable. Silicon materials often find use when semiconductor characteristics or devices are needed, and glass is the best material for sensitive optical detection or high voltage applications.

\section{RIGID POLYMERS}

Since their introduction into industrial use in the 1930's, thermoplastics have been refined and used for mass production of high quality goods. ${ }^{45}$ For this reason, much of the microfluidics research targeted at commercial applications has focused on creating devices that use rigid polymers as the bulk material. Many resources exist that describe the material properties of thermoplastics. Table 1 outlines the most common rigid polymers used in microfluidics and a few of their general properties. ${ }^{46-49}$ For more extensive information please see reviews by Gencturk et al. ${ }^{50}$ and Tsao. ${ }^{51}$

Polymethyl methacrylate (PMMA) is widely used in research laboratories because it is optically transparent and can be manipulated with fabrication methods such as hot embossing, laser ablation, or precision milling. This allows for prototyping at small scales of production, which is useful for a research setting, as demonstrated by $\mathrm{Wu}$ et al. ${ }^{52}$ However, the variability inherent in devices made by these fabrication methods often makes them unsuitable for large-scale commercial production. For example, channel roughness can be high (Figure 2A), and deformation during the heated sealing process increases variability between devices.

Methods that avoid channel roughness, like photolithography, require a cleanroom and have much slower prototyping cycles. Soft lithography with PDMS limits the need for a cleanroom but poses other challenges; for example, PDMS is soft, must be handled delicately to avoid tearing, and is chemically permeable. These issues make PDMS difficult to use as a template for patterning thermoplastics.

The transition from prototyping to manufacturing can complicate microfluidics development, as advances must be adapted for commercial production. To address this issue, some researchers seek to be involved in the commercialization process, while others focus their efforts on eliminating the prototyping-to-manufacturing transition altogether by making improvements to fabrication methods.

\section{Device Fabrication}

One area of extensive activity in rigid polymer microfluidics has been the use of solvents to improve bonding, modify surfaces, and reduce deformation. By carefully using solubility parameters, Yin and Wang ${ }^{53}$ formulated an acetone-ethanol treatment to adjust the Young's Modulus and harden a channel surface to a $\sim 150 \mathrm{~nm}$ depth below the surface. This resulted in reduced deformation during the sealing process and a device bond strength that could 
resist fluid pressures up to $\sim 30 \mathrm{MPa}$. Although this method was applied to nanochannel fabrication, it could be used in making microfluidic devices that require additional functionality from features that need to be preserved during the sealing process.

Another group developed methods to preserve surface modifications in ultraviolet/ozone treated devices for longer than 1 month $;{ }^{54}$ these treatments are desirable when plastic microchannels of increased hydrophilicity are required. They evaluated devices made from polycarbonate (PC), PMMA, and cyclic olefin copolymer (COC). COC and PC channel longevity was increased by dehumidified or vacuum storage, while PMMA channels were less affected. Additionally, they discovered that other factors such as treatment time or exposure to oxygen during storage affected channel integrity.

PDMS has been used as a mold for making epoxy devices that can withstand higher pressures than PDMS. Cheng et al. ${ }^{55}$ performed PCR in these epoxy devices and obtained better results than in PDMS; improved materials for use as epoxy molds are desirable because PDMS tears readily.

Since sealed channels are central to microfluidics, effective bonding of layers is essential for creating functional devices. Ganser et al. ${ }^{56}$ fabricated microfluidic devices from COC, a desirable polymer material due to its inertness, resistance to various solvents, and optical transparency. They found that bonding the $\mathrm{COC}$ sheets above the glass transition temperature $\left(T_{g}\right)$ caused channel deformation, while bonding below $T_{g}$ yielded low bonding strength. To address this issue, they used a decalin/ethanol solvent treatment within channels that enhanced bonding and channel integrity compared to oxygen plasma treatment. Su et al. 57 used an $n$-pentane/acetone mixture doped with $1 \mathrm{H}, 1 \mathrm{H}, 2 \mathrm{H}, 2 \mathrm{H}$-perfluorooctyl trichlorosilane to simultaneously increase the bonding strength and create a hydrophobic PC channel surface in a single step. This rapid fabrication technique could find use in applications like droplet microfluidics.

Another group tested a bonding technique with an even wider array of materials by sandwiching a dry film photoresist (Hitachi H-6230) between sheets, exposing the device to UV for crosslinking, and subsequently cleaning out the microchannels. ${ }^{58}$ This method was used to self-bond PMMA, polyvinylchloride (PVC), poly(lactic acid) (PLA), PDMS, and glass, as well as to hybrid-bond PMMA to glass, a difficult achievement. This approach works for single-use microfluidic devices, but the dry photoresist's solubility in organic solvents may constrain these devices to aqueous-based experiments.

Faghih and Sharp ${ }^{59}$ found that a solution of 20\% dichloromethane and $80 \%$ isopropyl alcohol (IPA), combined with a corona surface treatment, yielded good bond strength and optical transparency for affixing PMMA sheets together. While this technique is limited by the potential for microchannel collapse, another group found that filling PMMA microchannels with a hydrophobic amine-PDMS linker prior to ethanol submersion-assisted bonding prevented channel deformation, as seen in Figure 2B. For this latter method, bonded surfaces resisted pressures up to $12 \mathrm{MPa} .{ }^{60}$ As an alternative to high-temperature sealing methods, Liang et al. ${ }^{61}$ created ridges around formed microchannels on PMMA sheets with a $\mathrm{CO}_{2}$ laser and subsequently melted these protrusions through ultrasonic energy to bond 
two sheets. Images from a leakage test showed no fluid crossover between channels. This low temperature bonding method could allow assembly of devices containing enzymes or other predeposited reagents.

Polypropylene (PP) is desirable for biomedical applications because of its inert surface, but its softness has traditionally made PP difficult to manipulate effectively in the prototyping phase because thin sealing films sink into channels during heating. Voicu et al. ${ }^{62}$ demonstrated that film sagging can be avoided by increasing the thickness of the sealing layer. However, Sun et al. ${ }^{63}$ found that there is a tradeoff in film thickness and optical transparency, which is important for many assays. They also showed that hardened PDMS could be used to cast high-fidelity PP devices, shown in Figure 2C and Figure 3A, that sealed well when a spacer was used to control how much compression was exerted during the bonding process. Liang et al. ${ }^{64}$ developed a sealing method using a copper film that facilitated rapid heating, which allowed channels to be formed with a thin film without collapse (Figure 2D). Downsides are that the method requires unique equipment and the channel features are not as precise as those demonstrated by Sun et al. ${ }^{63}$ All three of these works show that it is possible to create quality microfluidic devices using PP.

These advancements demonstrate significant progress towards more robust fabrication of rigid polymer devices. Future studies should provide further optimization that will enable readily available fabrication techniques to create stable and effective microfluidic devices.

\section{Pressure Sensitive Adhesives}

Laser machining is a widely used method for rapid prototyping, although a downside is the roughness in the formed channels. Wu et al. ${ }^{52}$ sought to improve the precision with which laser ablation was applied by using three different protocols and found that machining PMMA with a laser at high power and speed produced the most consistent channels. Fan et al. ${ }^{65}$ showed that pressure sensitive adhesive (PSA) films could be patterned with features via laser ablation and then pressed together to form devices that could withstand $0.25 \mathrm{MPa}$ as shown in Figure 2E. While these devices are unsuitable for high pressure environments, the speed of prototyping shows promise for applications involving cell growth or lowpressure flows.

Ku et al. ${ }^{66}$ used a polyethylene terephthalate self-adhesive film that was placed over an area just larger than that of CNC-milled microchannels in a device. After applying the PSA, a liquid UV-sensitive adhesive was placed on the film and the device was covered with glass or PMMA. Subsequent UV exposure created an irreversibly bonded microfluidic device. In the future, this method should be tested for its stability in various solvents that might be used within devices. Aeinehvand et al. ${ }^{67}$ used PSA films in a centrifugal microfluidic device that isolated DNA from whole blood in an automated fashion, offering a compelling application. In future studies, the maximum pressure these devices can withstand should be addressed.

While these studies show the promise of rapid prototyping with PSA films to make microfluidic devices, future studies will need to evaluate these under more extreme conditions of pressure, $\mathrm{pH}$, solvents, etc., to broaden the range of suitable applications. If such uses are not established, researchers looking to create microfluidics for specific 
applications will continue to use well-established methods known to withstand the needed conditions.

\section{Fabrication Scaleup}

Microfluidics requires that useful devices eventually be made at a commercial scale, which can only happen as researchers look at mass production processes and the factors that affect them. Lauri et al. ${ }^{68}$ used optical coherence tomography to look at the effect of IPA and ethyl acetate on channel integrity in a commercial fabrication process. They saw clear evidence that the solvent opened pores beneath the channel bed in a nonspecific manner, which illustrated the challenges associated with these methods for general use in microfluidics fabrication.

Lee et al. ${ }^{69}$ examined the suitability of a faster variant of injection molding for prototyping of microfluidic devices, addressing both cost and design considerations (Figure 4). They created features in polystyrene (PS), PP, and COC from molds that cost $\sim \$ 3,000$. The paper also highlighted adjustments to device sealing protocols that could be useful for researchers looking to create designs with injection molding.

Two papers look at the increasing the rate by which different devices could be made taking a modular approach. In linking a ligase assay with PCR amplification, Lee et al. ${ }^{70}$ showed that PC prototypes could be assembled for sequential biochemical processes. Similarly, Gimenez-Gomez et al. ${ }^{71}$ demonstrated that microfluidic channels with multiple components could be formed by assembling a variety of blocks together on a breadboard, and then removing them after a PSA finished sealing. Devices could withstand pressures up to 0.5 $\mathrm{MPa}$. While both these papers show how prefabricated units could be used to accelerate the process of prototyping, questions remain about the suitability of these methods for production and assembly at a commercial scale.

Microfluidic droplet reactors are an area of research with strong commercialization interest. Ghosh et al. ${ }^{72}$ showed that a COC bubble reactor could be mass produced and could generate 1,300 droplets per second, which is competitive with similar devices made by more involved processes, indicating potential for general applicability. A different system reported by Sahore et al. ${ }^{73}$ demonstrated COC reactors that could perform $\beta$-galactosidase enzymatic assays using both magnetic and flow manipulation. This work is exemplary because it demonstrates reagent addition, target concentration, and rapid statistically relevant analysis. It would be exciting to see if digital PCR, for example, could be improved in these types of devices. The statistically powerful assays enabled by droplet microfluidics make them promising for developing commercially viable products.

Currently, there exists a gap between device complexity demonstrated in complete assay systems and that achieved through mass production methods. Recent research has narrowed the distance between these two, but work remains to be done.

\section{Applications for Synthesis}

Some of the most commonly used materials in microfluidics are problematic for biomedical and synthesis applications due to their high porosity and instability in solvents. ${ }^{62}$ Symborski 
and colleagues ${ }^{74}$ show one approach for using organic solvents with devices constructed with polytetrafluoroethylene (PTFE) substrates that were bonded together. They then carried out a reaction with benzophenone and methylmagnesium chloride in tetrahydrofuran; the products synthesized were subsequently examined by HPLC. This work is an important advance beyond testing devices with flowing colored dyes, which has limited utility for showing how a device will handle backpressure, extreme $\mathrm{pH}$, solvents, high temperature, etc. For the purpose of characterizing polymers, Wouters et al. ${ }^{75}$ immobilized trypsin and lipase on a porous monolith in a COC microdevice. This allowed them to degrade a polymer in $\sim 2$ minutes, much faster than was possible with other methods. Although the number of publications with a materials focus and applications in synthesis is still small, the ideas shown could have utility in many areas of microfluidics research.

\section{Applications for Biomedical Analysis}

One of the most prolific areas of microfluidics research has been biomedical analysis. Researchers have shown remarkable advances in creating devices for diagnostics, cell analysis, and more. It is crucial to have materials that are readily micromachined, but that still allow the growth of viable cells.

Lachaux et al. ${ }^{76}$ showed that soft thermoplastic elastomers could serve as the bulk material for biocompatible microfluidics. While their proprietary material, Flexdym, showed clear advantages over PDMS in many tests, it remains to be seen if this material will be competitive with other established biomedical device polymers.

Extraction of DNA from complex samples is an important pursuit in microfluidics. PerezToralla et al. ${ }^{77}$ showed that a magnetic bead-based device could capture cell-free DNA from serum, and subsequent PCR confirmed the presence of target genes. Campos et al. ${ }^{78}$ created a brass stamp that was used to emboss PC and COC into an array with high surface area (Figure 3B). UV light was then used to create surface carboxyl groups that aided in immobilizing DNA. The results of DNA extraction in this device were competitive with those from commercial kits.

Aoyama et al. ${ }^{79}$ used an imprint strategy to give PC, PMMA, and COC a rough surface that could be functionalized with antibodies and used to detect an inflammation marker from buffer and serum samples. They showed a limit of detection $0.1 \mu \mathrm{g} / \mathrm{mL}$ which is in the high range for serum biomarkers, and comparison to commercial kits hasn't been made yet. Lee et al. ${ }^{80}$ showed that protein levels in whole blood could be determined by capillary flow combined with a colorimetric assay that responded to the presence of proteins. The limit of detection was $25 \mu \mathrm{g} / \mathrm{mL}$; in future work this approach should be tested on clinical samples.

Odabasi et al. ${ }^{81}$ showed that eukaryotic cells could be grown on a mass-producible nonporous thermoplastic. They grew three different cell types in a PS microreactor and recorded responses to different conditions such as restricted nutrients or alkylation-induced DNA damage. The initial experiments were designed to be a foundation for studying cell cycle or cancer cell interactions, and this platform has promise for those studies. Moore et al. 82 created a microfluidic chip that held tumor fragments in an environment where they could flow immune cells or reagents past them while performing confocal microscopy. Because 
imaging was done in a flow system, the environment didn't require a permeable material like PDMS for gas exchange, while still mimicking a dynamic in vivo environment.

Trinh et al. ${ }^{83}$ detected E. coli in milk by capturing the bacteria through interactions with channel walls in a PS device, followed by lysis and amplifying target DNA. Although bacterial capture was demonstrated, clear advantages, like a lower limit of detection, would need to be established for this approach to gain traction. In related pathogen detection work, Knob et al. ${ }^{84,85}$ used porous polymer monoliths functionalized with capture DNA for the preconcentration of target sequences from a $100 \mu \mathrm{L}$ volume down to $3 \mu \mathrm{L}$. Captured DNA was labeled and observed via fluorescence microscopy. This sequence-specific process could be useful for various genetic analyses.

Many microfluidics applications for biomedical analysis are still in the proof-of-concept stage, but polymer devices are demonstrating consistent advances towards relevance in clinical settings. Key areas of future interest will be in scaling up production and reducing cost.

\section{Green Microfluidics}

With increasing legislation requiring manufacturers to reduce the effects of their products on the environment, methods for making microfluidics in sustainable ways are increasing in importance.

Sun et al. ${ }^{63}$ reported on making reusable PP chips for a simple antimicrobial susceptibility test (Figure 3A). For the purposes of evaluating reusability, it would be interesting to see side-by-side assays on both new and recycled devices. Wan et al. ${ }^{86}$ took a different approach to sustainability by developing a process to recycle PMMA for biomedical assays. They were able to show that the same bulk material could be cleaned, recycled, and used for up to 4 cycles without degradation of structural or optical characteristics. They also showed that viable cells could be grown in their devices at every stage of device recycling. This research addresses a significant issue because medical outcomes regarding cross-contamination, false positives, and avoidance of infection improved with the move to single-use devices. Importantly, this work shows that with appropriate consideration, it may be possible to reduce the long-term burden of such practices on the environment.

A novel strategy was presented by Andar et al., ${ }^{87}$ who used wood as the constituent material for a variety of microfluidic devices. A laser engraved a design into plywood which was then coated with Teflon, cellulose acetate, or PMMA. The channel was then glue-sealed to a silver-coated glass slide to allow detection. PMMA and PMMA-coated wood devices were compared, and no significant difference was seen between them, thus showing potential for wood to offer a low-cost, environmentally benign alternative to plastics. It will be important to see how such devices handle extremes of pressure, temperature, $\mathrm{pH}$, etc.

The field of green microfluidics is still at an early stage of development. We anticipate that advances demonstrating a thoughtful balance between effective applications and sustainable material practices will continue to reinforce positive contributions. 
Considerable effort in rigid polymer microfluidics has been aimed towards biomedical applications, although emerging work in synthesis and commercialization are seeing greater attention. It will be important to see technologies reach a commercial stage where they can have a higher impact on society.

PDMS

PDMS is the most used material in early-stage microfluidics research, because it is easy to mold, optically transparent, cheap, biocompatible, and good for prototyping. ${ }^{88}$ PDMS is elastomeric, and thin membranes can be used to create valves and pumps. ${ }^{89}$ PDMS has been used for droplet microfluidics, ${ }^{90}$ dielectrophoresis, ${ }^{5}$ transport control, ${ }^{91}$ etc. Soft lithography is the most common way of making PDMS devices, where features are created by casting PDMS on a mold, followed by bonding to another PDMS slab or a different planar material to make a device. ${ }^{92}$

\section{Devices}

Two emerging methods for making PDMS devices have received attention lately: roll-toroll ${ }^{93}$ and flexography. ${ }^{94}$ Roll-to-roll coats a paper roll with PDMS; a roll with a design then imprints the features into the PDMS. Devices can subsequently be cut out and a top layer of PDMS is added. Roll-to-roll molding is a quick way to make devices, but it requires considerable care for the equipment to ensure reproducible operation. Olmos et al. ${ }^{94}$ used a flexography-created mask to make epoxy resin molds. The molds were then used to create PDMS devices with channels as small as $10 \mu \mathrm{m}$; however, the channel surfaces were rough, limiting the scope of applications.

Sacrificial molding is another growing fabrication method where a three-dimensional design is made and encapsulated in PDMS to mold channels. Once the PDMS is hardened, openings are formed to reach the sacrificial mold, and a solvent is then loaded and dissolves the mold, leaving empty channels. Sacrificial molding is a quick method for making microfluidic devices, but it requires a 3D printer or other system to create the design, and each sacrificial mold can only be used once. Tang et al.$^{95}$ replaced nozzle tips in a 3D printer with customized stainless steel pieces having a desired channel shape (e.g., triangular, circular, etc.), and then acrylonitrile butadiene styrene (ABS) was extruded through the nozzle. PDMS was cast around the printed ABS, which was later removed via acetone immersion and ultrasonic cleaning, leaving an all-PDMS device. Goh and Hashimoto ${ }^{96}$ used a dual sacrificial mold; high impact PS was removed with limonene and polyvinyl alcohol (PVA) was removed with water, to form channels in a PDMS device with overhang structures and helical channels, illustrating complex geometries that can be achieved. This technique could be utilized in the future to mimic vascularized structures for biological studies, provided the feature size can be reduced well below the current millimeter scale. In other work, modular PDMS devices were made using a maltitol sacrificial mold. ${ }^{97}$ After forming maltitol structures, the print was cast, and cured PDMS was carefully peeled off of the sacrificial mold, then combined with a variety of modules to create a complete device. Modular devices were customized to illustrate their potential use in connection with biomembranes, soft electronics, and biological scaffolds. Presently, this method is limited by 
lengthy fabrication times for complex devices. Another group fabricated flexible microfluidic devices for potential wearable drug delivery applications. ${ }^{98}$ To form channels, they first printed a sacrificial mold composed of polyethylene glycol and methanol onto the substrate, which they subsequently covered with PDMS that was then cured. The sacrificial mold was later removed via heat and IPA, thus realizing the desired channel dimensions. They also demonstrated devices with resistive heating units by filling channels with a liquid metal. This work shows promising device fabrication, but application to analysis problems relevant to wearable devices is still needed.

Unlike sacrificial molds, a benefit of traditional molds is their ability to be reused. Speller et al. ${ }^{99}$ used xurography, which makes a design with a cutting plotter, to create molds that were then coated with PDMS and microwaved for curing. Although this allowed rapid PDMS microchip fabrication, it was limited to $>100 \mu \mathrm{m}$ feature dimensions. Molds have also been created on glass slides using two photon polymerization; ${ }^{100}$ the glass provides a substrate on which to build the mold, and PDMS is dispensed onto the mold and cured to make channel imprints. The device is then removed from the mold and bonded with a flat PDMS piece to create microchannels. Channel sizes as small as $\sim 5 \mu \mathrm{m}$ can be made using this method, although the $3 \mathrm{D}$ printer required for mold generation is expensive.

Despite its extensive use, PDMS is an adsorptive material, and many molecules can diffuse into it. Iyer and Eddington ${ }^{101}$ tested storage of rhodamine within PDMS over ten days. Rhodamine took over twelve hours to saturate a device and it remained fluorescent in PDMS devices. The slow saturation time conversely meant that it would take many hours to subsequently collect absorbed rhodamine, which might not be practical for many applications. Transporting oxygen in PDMS for use in an artificial lung is a promising application, and microfluidic devices have been designed to mimic veins within the lungs to transport blood and allow oxygen diffusion. ${ }^{102}$ These devices can withstand pressure and allow diffusion, but it would be difficult to produce enough devices to fully replace the function of veins within lungs and provide enough blood flow.

Controlling flow within microfluidic devices is important in many experiments. Majhy et al. 103 made oleophilic PDMS devices by applying n-hexane and candle soot to channel surfaces. Oils readily wet these channels, providing a suitable carrier fluid for water droplets to flow through in droplet microfluidics. Another way of changing flow is to put features within microchannels. Lolsberg et al. ${ }^{104}$ made spinnerets and webbing within PDMS devices to control the location where a fluid would enter the flow of another stream to enhance mixing. Their focus was on polymer fiber synthesis, but this could also be useful for adding dye or reactants within a modular microfluidic system.

Another way of controlling fluid flow is the use of acoustics. A trap can be made within a device to capture droplets; the trap is then used as an acoustic actuator to push a droplet, causing flow while pulling in another droplet for capture. ${ }^{105}$ Only one trap was used for this experiment, but if more were made and connected, multiplexing could be feasible. Another way acoustics have been used involved forming a hairpin in a channel, where cells could be identified by their resonant frequency. Liu et al. ${ }^{106}$ detected cancer cells on the basis of differences in their resonant frequency from the buffer. The hairpin could detect cancer cells 
and determine their numbers, but upstream sample preparation and clear differentiation between different cell types would be needed for use as a clinical cancer diagnostic test.

PDMS microdevices have also been used to detect bacteria, as well as their proteins or DNA. Singh et al. ${ }^{107}$ coated microchannel walls with graphene oxide wrapped around carbon nanotubes to bind bacteria. The capture antibodies were stable for at least one week without degradation if maintained at $4{ }^{\circ} \mathrm{C}$. This method is promising but has yet to be tested beyond model samples. Bacteria were also analyzed using a cell lysis and DNA capture process wherein chitosan-coated magnetic particles were mixed with a sample of bacteria inside PDMS microchannels. ${ }^{108}$ A mechanical vibrator caused cell lysis, and $97 \%$ of the DNA was then extracted on the particles and analyzed with gel electrophoresis. This lysis process was quick and could be made more powerful through coupling with other microfluidic elements that better automate DNA detection. Lastly, mycotoxins at levels harmful to humans were detected in an immunoassay microfluidic chip. ${ }^{109}$ Toxin concentrations were determined using a smartphone camera that detected colorimetric differences in the immunoassay. The sample preparation before loading in the device involved liquid-liquid separation to extract mycotoxins from food, so this work could benefit from automation of the process.

Biomolecules, from small molecules to proteins, have also been analyzed in PDMS devices. Cholesterol was detected as it was oxidized on $\mathrm{NiO}$, and current changed with cholesterol concentration. ${ }^{110}$ Performance could be improved with optimization of channel dimensions and flow. Glucose was detected in real time in a different system where islets within a channel reacted with glucose and influx was monitored. ${ }^{111}$ This system could be used to better determine when insulin should be administered or when a person should eat. Infrared spectroscopy was also used in PDMS devices to monitor enzyme kinetics. ${ }^{112}$ Because the material was strongly absorptive, devices had a thin layer of PDMS to facilitate detection. This approach could be useful in droplet microfluidics to monitor reaction kinetics within droplets. Another promising health-related application is evaluation of preterm birth risk. Sahore et al. ${ }^{113}$ made a solid-phase extraction monolith to retain preterm birth risk biomarkers and fluorescently label them. The labeled biomarkers were eluted and then separated using $\mu \mathrm{CE}$ with all analysis steps automated. This work shows excellent promise for integrated microfluidic analysis, but will need to be expanded beyond the two biomarkers studied.

DNA analysis can be used in disease diagnosis. Ma et al. ${ }^{114}$ made PDMS channel devices with a clear glue top; the devices were used for loop-mediated isothermal amplification. The microchannels were made hydrophilic, and maintained their properties longer than six months in dry storage. This method could detect down to $\sim 10$ nucleic acid copies within 30 $\mu \mathrm{L}$; additional work to identify specific bacteria strains could make this a more powerful diagnostic tool. Using a different approach, Ning et al. ${ }^{115}$ made PDMS/glass digital PCR devices. These devices used a water channel under the PCR microchannel to keep fluid from evaporating during a run. The PCR microchannel was also degassed to allow sample to flow through without applied pressure and to avoid air bubbles during heating. This device required some expertise to run but could potentially become useful for clinical diagnostic tests. 
Droplet microfluidics have been pursued in PDMS microdevices over many years. Triple emulsion droplets were made using surfaces coated with hydrophilic poly(allylamine hydrochloride) and poly(acrylic acid). ${ }^{116}$ The coating lasted six hours before it needed to be reapplied. This work showed that triple emulsion droplets could be made; future applications in DNA analysis or biosensing might be promising. Detection of molecules in air was performed by using a gas-liquid droplet method so the liquid picked up target analytes. ${ }^{117}$ Using this method, ammonia was detected at $500 \mathrm{ppm}$; other airborne analytes should also be tested and their detection limits measured. Parylene was used to coat the outside of a PDMS device to control diffusion into and out from the channels. ${ }^{118}$ The coating slowed liquid evaporation from channels, and anerobic cells could grow in the droplets. Further reductions in droplet and channel size will be needed for improved applications.

PDMS devices can now be made with both conventional and new methods of fabrication. Detection has also been improved with different methods such as acoustic, spectroscopic, and electrochemical techniques. The ability to combine these advances with the extensive body of work in PDMS microfluidics should lead to more integrated analysis systems.

\section{Valves and Pumps}

Valves and pumps are important components of microfluidic devices, as they control the movement of fluids by regulating flow rate and path switching. The elasticity of PDMS makes valves and pumps easy to form and use in microfluidic chips. Briefly, PDMS valves contain a thin membrane that can be deflected to block a microchannel and displace liquid.

PDMS pneumatic valves were recently used to control droplets for on-chip single-cell analysis. Sun et al. ${ }^{119}$ designed 12 pneumatic valves that were two PDMS layers thick for regulation of droplets in a microfluidic device, and used it to perform cell immobilization in calcium alginate. After cell capture, they performed fluorescent staining to confirm if target cells were living or dead. This system is useful in biological assays because it can both immobilize cells and prevent damage caused by hydraulic forces acting directly on cells. PDMS valves can also split droplets selectively. Raveshi et al. ${ }^{120}$ reported a mushroomshaped valve created with a $30 \mu \mathrm{m}$ membrane thickness to split droplets in a PDMS device. Following application of pressure, the valve membrane deformed, which altered the channel geometry and caused a droplet to split selectively. This splitting system is advantageous because it is simple and can be integrated with other microfluidic functions, although application to more biologically relevant samples remains to be done. Li et al. ${ }^{121}$ developed a microvalve oscillator that was built from three PDMS layers: a top channel, a chamber on the bottom, and a $30 \mu \mathrm{m}$ elastomeric membrane in between. Switching the valve between open and closed states created pulsatile outflow from constant inflow, which allowed filtration of plasma for 1 hour. Combination of this plasma filtration system with other analysis processes could be beneficial.

PDMS valves have also been used to control flow within microfluidic devices for cell culture. Dettinger et al. ${ }^{122}$ designed two PDMS layers that contained a four-valve peristaltic pump to permit fluid manipulation for culture of both adherent and suspended cells. Using these valves, they controlled culture conditions in 48 chambers across a chip. Subsequent work to study the limits of scaling cell chamber numbers would further establish the utility 
of this approach. Others have integrated valves in microfluidic devices to trap and release cells. Wang et al. ${ }^{123}$ presented a microdevice to monitor intracellular calcium signal under ATP stimulation; pneumatic valve traps in the chip controlled capture and release of individual cells. It could be advantageous to expand beyond a single trap to capture many cells in parallel. Li et al. ${ }^{124}$ designed a PDMS microfluidic chip fabricated by soft lithography with pneumatic microvalves that controlled flow to manipulate cells. They were able to culture three different types of cells in the device for 4 days. Automation of fluid delivery steps would facilitate biological applications. In other work, Papadimitriou et al. ${ }^{125}$ utilized capillary flow-based valves where channels intersect to pattern an antibody in a PDMS microchip. They demonstrated antibody attachment by flowing labeled antigen through the channel and measuring fluorescence. This device is advantageous because antibody is patterned in the finished device, instead of before bonding steps that could denature the antibody. In future work this approach could be demonstrated in quantitative immunoassays instead of only with model analytes.

Lee et al. ${ }^{126}$ developed a microfluidic device that mimicked flow in the heart to replicate shear stress. The PDMS chip consisted of a set of ten microvalves designed to provide flow characteristics like those observed during atrium and ventricle actuation. In this system, they exposed cultured porcine aortic valvular endothelial cells to various shear stress profiles. The chip worked well for its intended application, and it would be made more powerful if shear experiments on 3D tissue mimics were performed.

Coupling microfluidic devices to mass spectrometry (MS) can provide enhanced analytical capabilities and applications. Wei et al. ${ }^{127}$ integrated solid-phase extraction with electrospray ionization on a valve-controlled PDMS microdevice. Magnetic beads having silica surfaces were retained by magnets and used to preconcentrate the herbicide, quinotrione, for MS analysis, with the pneumatic valves providing automation and controlling fluid flow. This device could be useful in the growing field of MS analysis, provided the multiple connections to the chip can be simplified.

In another study, Xu et al. ${ }^{128}$ reported a new fabrication technique for valves in a microfluidic device for cell analysis. Device fabrication used a printed circuit board and PDMS, with 100 microchannels, three independent control channels, and two inlets in each unit. They controlled 100 reactions in parallel in one unit and used single-cell PCR to detect mutations in lung cancer cells. This method of fabrication appears straightforward to apply in research labs, but may require materials other than PDMS for larger-scale usage.

Guler et al. ${ }^{129}$ fabricated a microvalve by forming a hole through a cylindrical PLA rod and then inserting it through a microdevice as seen in Figure 5. Positioning the valve allowed control of flow focusing and microdroplet sorting in the microfluidic chip; some optimization was required for implementing the valve with PDMS vs. PMMA channels. This plug microvalve is advantageous because it works with different microdevice materials and can withstand pressures up to 2 bar; however, it is limited by manual operation and slow response. 
The elasticity of PDMS makes it the dominant material for microfluidic valves and pumps that control flow. Applications for these components involve cells, droplets, sample preparation, etc., and their use when integrated in microdevices can provide automation.

\section{DEVICES FORMED FROM MULTIPLE MATERIALS}

To increase device functionality many researchers incorporate multiple materials in the fabrication process. The use of multiple materials allows inclusion of valves, heating elements, and other features that increase the scope of applications that can be addressed with microfluidic technologies.

\section{Membranes}

Membranes in microfluidic systems can be fabricated from several materials, including inorganic, organic, or combinations. Bunge et al. ${ }^{130}$ designed a $3 \mu \mathrm{m}$ thickness porous membrane made of aluminum oxide for cell culture. The membrane was gas permeable and sandwiched between two closed microfluidic chambers. Because of the membrane gas permeability, HaCaT-cells could be cultured in the device. Although the chip material was compatible with cell growth, the fabrication process was not straightforward. Chun ${ }^{131}$ demonstrated rapid and selective ion transport by implementing a $30 \mu \mathrm{m}$ length, porous poly-styrenesulfonate membrane in a microfluidic channel. The membrane was fabricated by photolithography and had low hydraulic and electrical resistance. The membrane was evaluated in preconcentration of model fluorescent molecules and proteins; this membrane could also be integrated with electrophoretic separation due to its compatibility with many buffer solutions. Remcho's group ${ }^{132}$ patterned polycaprolactone-filled glass microfiber membranes in microfluidic devices. The membranes were sandwiched between low-cost top and bottom layer tape materials designed to selectively allow exposure to an oxygen plasma, which altered the surface properties. A colorimetric total protein assay allowed measurement of protein concentrations in blood. Although they were able to fabricate microdevices with low-cost materials, application to assays with lower detection limits would be desirable. In another study, Malankowska et al. ${ }^{133}$ reported a microfluidic device for blood oxygenation. They developed a double-sided PDMS membrane that increased oxygen diffusion, and they were able to oxygenate sheep blood up to $98 \%$ saturation. While the microfluidic chip was successful in blood oxygenation, significant future work will be needed for medical applications. Membranes in microfluidic devices have been used for molecular analysis, cell experiments, and organ mimics; future applications in chemistry and biology are promising.

\section{Valves and pumps}

Valves and pumps can also be created in hybrid microfabricated devices for a variety of applications. Using different materials in a chip can be advantageous because unique properties can work together to generate a more useful device; such pumps and valves can control the flow of multiple solutions inside a microdevice.

Im et al. ${ }^{134}$ integrated PDMS microvalves and a pump on a PMMA chip to carry out an immunoassay. The micropump and valves were controlled by an external roller that enabled fluid actuation through the PMMA chip, for detection of cardiac troponin T. This platform 
has promise for point-of-care analysis, provided the roller mechanism can be made more elegant. Lee et al. ${ }^{135}$ developed a microfluidic pumping system by designing a replicamolded PDMS suction cup placed on an outlet channel. Pressing the cup deformed the PDMS, drawing liquid through PMMA or PS channels, allowing water-in-oil droplet generation. The device simplicity is promising for resource-limited applications, although better flow rate regulation may be needed. Another group integrated two types of valves on a PMMA chip to carry out RNA extraction. ${ }^{136}$ The PMMA chip was further combined with a silica membrane to adsorb nucleic acids, along with an ultrasonic system to lyse cells and release nucleic acid samples in $<1 \mathrm{~min}$. Although rapid results were achieved, a simpler design would be better suited for point-of-care applications.

Pramanik and Suzuki ${ }^{137}$ developed a $50 \mu \mathrm{m}$ PDMS diaphragm placed on solution reservoirs in a glass microdevice, where deforming the diaphragm caused solution exchange within microchannels. This platform could detect human interleukin 2 in 25 minutes down to 100 $\mathrm{pg} / \mathrm{mL}$, a diagnostically useful level, but manual diaphragm operation might limit reproducibility. Another team reported a thermally actuated microvalve that used a phasechange material, paraffin wax. ${ }^{138}$ The valve was actuated by melting of the paraffin, and it was tested under various pressure and flow control conditions. Application beyond model dyed fluid streams will be essential for this method to see broader usage.

PDMS was integrated with rigid polymer microchannels to facilitate on-chip fluorescence labeling and $\mu \mathrm{CE}$ of preterm birth biomarkers in 1 hour. ${ }^{113}$ The PDMS fluidic and control layers had a peristaltic pump and pneumatic valves to control fluid inputs into a COC microchannel that had a hydrophobic porous polymer monolith. Using this automated and integrated design, they were able to preconcentrate, label and separate two preterm birth biomarkers. A more scalable device fabrication method would be needed for clinical implementation.

A shape-memory polymer was fabricated into a PDMS film and bonded to an indium tin oxide surface to make a two-state logic device. ${ }^{139}$ The valve was used for switchable particle control via the shape memory polymer's deformation and return to its native state. It will be exciting to see if this method can be used in bioanalysis applications.

Pinto et al. ${ }^{140}$ integrated pneumatic valves, a Si photodiode, and an agarose bead packed column in a PDMS/glass microfluidic device for optimizing chromatography conditions. The pneumatic valves allowed reagents to pass through the column, capturing a monoclonal antibody from cell culture. It would be useful in the future to develop valves for use in microchip chromatographic applications at higher applied pressures.

Combining different materials with PDMS valves or pumps in integrated devices can be advantageous and useful. The combination of materials allows components to provide functionality and desired channel properties. Future devices should continue to utilize diverse materials to automate and improve analysis processes. 


\section{Hydrogels}

Hydrogels can be used in creating microfluidic component functionality, in addition to serving as solid device structures. Hydrogels have been used as semi-permeable barriers, smart valves, and sensors within devices comprised of other materials. For the factors influencing a hydrogel's suitability as a sensor or actuator, we refer readers to the work of Ehrenhofer et al. ${ }^{141}$ on hydrogel swelling. Yang et al. ${ }^{139}$ showed that acrylate shape memory polymers could be used to direct sample flow within a device. The hydrogel was shown to be water-tight, and localized heating of the hydrogel could redirect sample flow in the device. Simon et al. ${ }^{142}$ suspended multiple enzymes in hydrogels that could then be patterned before encasing in a microfluidic channel. This strategy allowed them to demonstrate an enzymatic cascade, and activity of immobilized enzymes was maintained for $\sim 10$ days. Expansion beyond the model cascades initially demonstrated would be of value. An alternative use of hydrogels was demonstrated by Berry et al. ${ }^{143}$ In this proof-ofprinciple study, hydrogels acted as a semi-permeable barrier to allow simultaneous culture of distinct cell populations. Diffusion of small molecules across the hydrogel was possible, while cells remained in place. Future studies tracking how cell signaling markers change over time between two populations could be an interesting application for this technology. Hydrogels provide the useful ability to be barriers that are permeable, flexible, or both. Hydrogels are also enabling in the creation of valves, pumps, and other components.

\section{Miscellaneous Applications}

By combining multiple materials carefully, it is possible to fabricate devices with complex functionality. Aeinehvand et al. ${ }^{67}$ created two-material, reversible valves that were adjusted by a screw, which allowed the breakthrough pressure to be tuned to a specific centrifugal speed. This approach facilitated a fluorescent antibody-based assay that tested for five peptides found in human serum. The chip was made of a combination of PMMA, PVC, and PDMS sealed together with a PSA. For broadest application, the screws will need to be calibrated to provide highly tunable flow resistance. Brassard et al. ${ }^{144}$ used a thin film placed on top of a proprietary thermoplastic to create a centrifugal microfluidic chip that could be attached to a centrifuge outfitted with 8 pneumatic lines. This allowed them to carry out the steps of DNA extraction on a centrifugal chip, with results similar to those of a plasmid miniprep, but offering better recovery percentages than commercial kits. Lei et al. 145 used photolithography and gas-phase processes to create an insulated indium-tin oxide microheater surrounding a temperature probe on glass that was attached to a PDMS microfluidic device. The system could localize heat to a single oocyte and study the effects of temperature on oocyte permeability; this approach could be used generally for heating applications in microdevices. Alsharhan et al. ${ }^{146}$ used two-photon laser polymerization to make structures such as bellows, orifices and interwoven microchannels inside enclosed hot embossed COC microchannels (see Figure 6). These structures allowed flow manipulation in microchannels, and the interwoven channels could find use in simulating organ functions in a microdevice. The utilization of multiple materials can help to generate complex microdevices for application in promising assays, but the processes and devices require further optimization. 


\section{THREE-DIMENSIONAL PRINTING}

Traditional fabrication methods such as soft lithography have been used extensively to create microfluidic devices, but 3DP is emerging as a powerful technique that may overcome barriers that have historically limited microfluidics research. For example, 3DP facilitates prototyping of devices at lower cost and reduced fabrication time compared to techniques like soft lithography or hot embossing. Additionally, complex three-dimensional structures can be created through 3DP, without the need for a restrictive environment such as a cleanroom. This section will review recent advances related to materials and their application in the field of 3DP for microfluidics. Three main 3DP technologies will be discussed: fused deposition modeling, PolyJet, and stereolithography. A summary of many of the materials described in this section is found in Table 2.

Each 3DP technique first requires creation of a computer aided design rendition of the proposed microfluidic device, later converted to a stereolithography file, which the printer then uses to create the specified structures. FDM functions by feeding a solid filament through a heated nozzle and depositing the material on a substrate, allowing sufficient time for the material to solidify before the next layer is printed. SLA utilizes a laser or projected light image to polymerize layers in a liquid resin. After hardening one layer, the build platform moves vertically so liquid resin engulfs the solid layer, which allows the next layer to be polymerized, a process that is repeated until the device is complete. Finally, PJ prints by jetting a liquid photocurable resin, which becomes solid after exposure to UV light. As shown below, each of these 3DP techniques employs various building materials and possesses unique advantages and disadvantages regarding the fabrication of devices.

\section{FDM}

FDM can be the least expensive and most user-friendly 3DP method, making it attractive in both research and industry. However, use of FDM to make microfluidics has been limited by factors such as insufficient feature resolution and low optical transparency of build materials. Much of the work done in the last two years has focused on making this cost-effective technology more accessible to a wide variety of users, demonstrating the utility of various FDM materials, and developing unique biomedical applications.

To improve the optical transparency of FDM-generated devices, Bressan et al. ${ }^{147}$ directly printed PLA onto a transparent sheet of PMMA, which, due to the similar composition of the two materials, achieved strong bonding with no observable channel leakage. The PMMA window afforded optical transparency in the microchannels, and the procedure avoided complex bonding processes, although successful bonding was limited if less expensive PMMA sheets were used. Lynh and Pin-Chuan ${ }^{148}$ utilized a solvent-assisted approach to bond PLA and PMMA by spin coating ethanol on the two sheets, then heating and exposing the device to UV light. The devices, seen in Figure 7, stayed bonded up to 1.3 MPa and had good optical transparency. Applications of this fabrication procedure included making nonplanar micromixers, double emulsion generators, and serpentine channels. Future work should focus on demonstration of applications that involve more complex mixtures. In an effort to overcome the traditionally poor resolution of channels in FDM-printed devices, 
Nelson et al. ${ }^{149}$ used thermoplastic polyurethane (PU), directly extruded onto a build platform, to fabricate channels with dimensions between 40-400 $\mu \mathrm{m}$. Although they overcame sagging by designing stair-like steps at the top of the channel, further optimization would be needed to reduce the impact of channel roughness and create truly threedimensional fluidics.

With a wide variety of materials available for use in FDM-fabricated devices, many researchers have sought to characterize the advantages, disadvantages and applications of these materials. Salentijn et al. ${ }^{150}$ characterized important qualities of 12 FDM materials including fluorescence, solvent resistance, and biological compatibility. They discovered that the majority of these FDM materials were compatible with methanol and IPA, but Arnitel, a thermoplastic copolyester, was the only material compatible with every solvent tested. PVA was the most problematic material, as it was incompatible with all solvents, cells and tissue slices tested. In another study Romanov et al. ${ }^{151}$ classified four FDM materials, composed of either a PLA or polyethylene terephthalate glycol base, for transparency and pressure tolerance. Every material tolerated significantly higher pressure than PDMS-glass devices. Polyethylene terephthalate glycol from t-GLase could withstand nearly double the pressure of the other materials at $5.5 \mathrm{MPa}$; however, it was the least transparent material, while CC PLA was found to be the most transparent.

Whereas the previous two studies compared the properties of various FDM materials, Goh and Hashimoto ${ }^{152}$ sought to demonstrate general usability of FDM to create devices composed of polymers with different characteristics. Using a water soluble PVA sacrificial mold technique, they fabricated T-junction devices in PU, epoxy, an optical adhesive, PDMS, gelatin, and polyethylene glycol diacrylate (PEGDA). Thus, FDM can be used to make molds for hard polymer, soft polymer, and hydrogel materials that are heat or UV curable, although issues associated with sacrificial fabrication remain. Two of these comparison studies mentioned that the principal limitation of FDM was channel resolution, which is still a major concern, although recent customizations have demonstrated channels as narrow as $40 \mu \mathrm{m} .151$

While much attention has been focused on FDM microdevice fabrication, many groups have employed FDM to make fluidic devices for specific analytical applications. Bressan et al. ${ }^{153}$ printed PLA microstructures on a PMMA sheet to create a serpentine microfluidic device to synthesize gold and silver nanoparticles. They used two syringe pumps to control flow of reducing agent and metal salt, each in their own channel initially, and later combined into a serpentine channel for mixing. Segmented flow in the metal ion channel prevented deposition of metal where the two channels converged. The synthesis of nanoparticles in 3D printed devices has promise for broader application.

Other groups interested in the analytical potential of FDM-printed fluidic devices have found ways to imbed microelectrodes for measurement purposes. Duarte et al. ${ }^{154}$ printed an electrode on a build platform using PLA doped with carbon nanotubes. Then, ABS was printed onto the microelectrode and remainder of the designated build area to form channels. This integrated system was successfully used for capacitively coupled contactless conductivity detection in determining oil and water droplet sizes. These devices might be 
useful for more complicated droplet microfluidic experiments, but parameters such as channel flow need to be further optimized to make this possible. Another group created PLA devices that integrated silver electrodes. ${ }^{155}$ Fabrication entailed three steps: $3 \mathrm{DP}$ of a portion of the device with a cut-out for the electrodes, pausing the print and screen printing and drying the Ag electrode material into the specified location, and continuing 3DP of the device. The devices fabricated in this study were used to measure the sulfide content in river and sea water. Compared to a commercially available sensor, the measurements were not appreciably different, confirming suitability for use in electrochemical assays.

FDM technology has also been applied to biomedical analysis. Singh et al. ${ }^{156}$ fabricated microfluidic devices made of silicone to allow detection of biomarkers from whole kidneys. These devices were made via silicone extrusion onto the surface of a 3D printed replica of the kidney to be studied, which resulted in a conformal layer that matched the surface of the actual kidney. The use of silicone was integral to creating a flexible device that could mimic the surface of a kidney. This device allowed measurement of biomarkers from the kidney that inferred information about its ischemic condition and metabolic activity. This method could be used to create biomarker sampling devices for other organs or to monitor the condition of organs meant to be transplanted.

During the past two years, significant work has been performed to overcome FDM limitations such as large feature sizes and low optical transparency. Methods are now available to create devices with smaller channel dimensions, as well as those that can succeed in optically detected assays. Thus, this user-friendly and relatively low-cost 3DP method shows significant potential for point-of-care applications.

\section{SLA}

SLA uses patterned light to polymerize thin sections of resin, layer-by-layer onto a moving platform. Key to many forms of SLA is an absorber, which is needed to attenuate the light so it does not penetrate into printed layers and polymerize the unpatterned void features.

Bhattacharjee et al. ${ }^{157}$ showed that PDMS can be formulated into a SLA resin, which maintains PDMS-like properties after being printed, despite the addition of an absorber. Using this resin and a custom printer, they were able to make different structures including blocks and pyramids with or without supporting internal material. A fluidic device was also made to culture mammalian cells as shown in Figure 8. Some drawbacks to this resin are its relatively large minimum feature sizes $\left(500 \times 500 \mathrm{~m}^{2}\right)$ and its swelling in solvents. Kotz et al. ${ }^{158}$ printed PTFE methacrylate devices with a variety of photoinitiators to compare the swelling to that observed in traditionally made PDMS devices. These devices swelled less than PDMS in most solvents, but had poorer optical transparency than PDMS. Better visible light transmission characteristics will be needed for these 3D printed devices to find broader usage.

Some resins do not have absorbers that interfere with visible wavelength measurements; devices made from these optically clear resins have been used to detect bioluminescence related to ATP. ${ }^{159}$ A silicon photomultiplier was added to the device to detect the 
luminescence and determine the concentration of ATP at low nanomolar levels. Analyses in these devices are rapid but extension to clinical or other medically relevant samples still needs to be shown.

Multicellular tumor fragments have been captured in 3D printed devices by changing channel widths. ${ }^{160}$ A sample was loaded into a device until it reached a zone where the fragment couldn't pass through, and was immobilized there and analyzed. These devices worked well for tumor fragments $>350 \mu \mathrm{m}$; improved fabrication to make much smaller channels would be needed to capture individual cells. Beauchamp et al. ${ }^{161}$ demonstrated much smaller 3D printed particle trapping device features using a resin first formulated by Gong et al. ${ }^{162}$ The traps had $30 \mu \mathrm{m}$ openings on one side with a $10 \mu \mathrm{m}$ gap on the back to capture $25 \mu \mathrm{m}$ beads but let smaller particles flow through. Trap designs were varied and tested to see which ones collected beads most effectively. In future work it would be useful to develop these traps to capture cells so they can be examined individually.

Two recent publications demonstrate the power of 3DP of truly microfluidic features. Beauchamp et al. ${ }^{163}$ used a PEGDA resin to make $\mu \mathrm{CE}$ devices with $37 \times 50 \mu \mathrm{m}^{2}$ channels, assisted by an exposure compensation pattern on the edges of the channels, which received a lower light dose than the bulk of the layer. They rapidly separated preterm birth risk biomarkers by $\mu \mathrm{CE}$ and compared performance to that in other common $\mu \mathrm{CE}$ device materials. This is the first demonstration of $\mu \mathrm{CE}$ in a $3 \mathrm{D}$ printed microfluidic device; improvements in surface properties may further advance these systems. Parker et al. ${ }^{164}$ also used PEGDA to 3D print microchannels with a narrow groove formed over a small segment of each channel to allow UV light to penetrate the device and polymerize a monolith. The UV absorber in the bulk material acted as a mask, thus preventing monolith polymerization in other regions in the channel. Polymerized monoliths were used for immunoaffinity capture of preterm birth biomarkers from blood serum. This work could be advanced by integrating separation with the on-chip sample cleanup step.

For many 3D printed devices, an off-chip pump is used to flow liquids. Gong et al. ${ }^{165} 3 \mathrm{D}$ printed a PEGDA resin with pumps and valves that were comparable to those made in PDMS. Valves were deflected with 9 psi and could be actuated $>1,000,000$ times without breaking. The authors further showed that different 3D printed microfluidic chips could be interfaced with each other, so that exterior features matched up and connected microfluidic and pneumatic channels between devices. ${ }^{165}$ Future application of these devices to analytical or biological problems would be desirable.

SLA shows highly promising results for 3DP of truly microfluidic devices that have been applied in a number of biologically relevant problems. Most SLA-fabricated devices aren't fully transparent to visible wavelengths, but progress toward printing less absorptive devices is ongoing. Many materials can be used in SLA, and 3D structures can be made within a device, although few applications to date have taken full advantage of the third dimension. 
In terms of advantages and disadvantages, PJ 3DP falls somewhere between FDM and SLA. Although PJ 3DP achieves smaller feature dimensions than FDM, PJ does not offer resolution as good as that achievable with SLA. PJ printers are generally costlier than FDM ones, and can be as pricey as high-end SLA systems. PJ has diverse options for build materials, including those that are biocompatible. However, PJ fabrication of microfluidics has historically been limited by lengthy processing steps after printing. Much work has occurred over the last two years to make PJ 3DP more user friendly and to implement this technology in a variety of applications.

To overcome the lengthy post processing typical of PJ printed devices, Castiaux et al. ${ }^{166}$ developed two methods of fabrication that require minimal to no post processing. One technique involved first printing an open-faced microchannel, and then filling a solution of glycerol and IPA into the feature as a liquid support material. Alternatively, a thin PC membrane support was placed over the microchannel area. Both methods provided structural support that the channel needed while the resin was being cured, and in both cases, printing was then resumed to complete the device and enclose microchannels. As a demonstration of PJ's potential for multimaterial printing, open ports for tubing were formed at each end of the channel using a different material from the bulk of the device. Y-shaped mixers and serpentine devices were fabricated and applied for measuring ATP release from red blood cells. This study shows that PJ-printed microfluidic devices can be made to avoid timeconsuming post-processing steps, but better control over channel shape and dimensions is still needed.

Because the mixing of fluids is critical in many microfluidics applications, Enders et al. ${ }^{167}$ compared the performance of five mixers: "T", caterpillar, enhanced caterpillar, Tesla-like, and "HC". Although the Tesla-like mixer could achieve the fastest overall mixing times, they were only achieved at the highest flow rates. The $\mathrm{HC}$ mixer, on the other hand, performed well over all flow rates, and performance did not depend on flow rate, unlike for the other four mixers. This makes the $\mathrm{HC}$ mixer potentially useful for biological applications that need mixing to occur in a low shear stress environment. All the tested mixers are constrained by parameters such as channel length and internal volume, so further optimization is warranted.

PJ has recently been utilized to 3D print devices for biochemical applications, including gel electrophoresis. Walczak et al. ${ }^{168}$ used a VisiJet resin to make T-shaped devices for gel electrophoresis assays. Channels had better resolution when printed in high- compared to standard-definition mode, but the smallest channels still had several hundred microns widths. Combined with active device cooling, gel electrophoresis of a DNA ladder was done, albeit with significantly lower performance than prior microdevice DNA separations. In 2019, the same group expanded on this result to form a "Lego"-like modular device for DNA gel electrophoresis. ${ }^{169}$ Although the separation performance was inferior to that in their previous paper, this approach made it possible to remove a "brick" from a device after one analysis and transfer it to another modular system for further characterization. Both of 
these studies show promise, but remain limited in their separation performance because of the large channel cross sections.

Recent work has made PJ 3DP a more broadly useful technology for making fluidic microdevices. With development of fabrication techniques that limit post-processing, PJ devices can now be made more easily and rapidly. Furthermore, optimized mixer designs show potential for various fluidic assays. In the future, PJ 3DP will need to achieve higherresolution fluidic features to create high-performance microfluidic devices and take full advantage of the broad suite of materials that can be created with these printers.

\section{Combining Multiple 3DP Methods}

Combinations of 3DP methods have been used to fabricate modular microfluidic devices. Munshi et al. ${ }^{170}$ created a combined PJ and FDM device for measuring endothelial cell ATPmediated nitric oxide release. The system was composed of three modules: cell growth, sample loading, and electrochemical detection, all fabricated by PJ and connected through threaded ports, while the rotor in the sample injection module was made via FDM. Ji et al. 171 created a modular double emulsion generator using SLA and PJ methods. Different functions could be achieved when one of three modules was incorporated: single inlet, pneumatic control, or dual inlet. The single-inlet and pneumatic-control modules both produced double emulsions with a varying number of concentric droplets. A module with two inlets created double emulsions with inner droplets having different compositions. Combining 3D printed materials in a modular approach offers utility for biological applications and leverages the advantages of each method. In future studies it would be desirable to decrease feature sizes and develop novel ways for connecting modules.

\section{Printer Comparisons}

With the ever-expanding array of possibilities it is increasingly important to compare and contrast devices fabricated by different 3DP methods. ${ }^{172}$ Zeraatkar et al. ${ }^{173}$ made the same serpentine micromixer design using FDM, PJ and SLA to compare performance. The devices were tested for mixing at different flow rates and Reynolds numbers; all resulted in fluid mixing, but the FDM and PJ devices worked more effectively at lower flow rates, while the performance of SLA devices was independent of flow rate. Future studies should similarly explore mixing completeness in other device geometries and expand beyond simple mixing of dyed solutions. Another group compared devices from three different 3DP methods in generating emulsion droplets. ${ }^{174}$ Feature resolution in the $x-y-z$ planes in the droplet generators was compared to that in devices created by micromilling. Micromilled devices had the smallest channel dimensions $(50 \mu \mathrm{m})$, and SLA devices had the best performance and channel resolution $(\sim 350 \mu \mathrm{m})$ of the 3DP methods. Although fabrication of these devices using low-cost 3D printers is appealing, many applications will require higherresolution and costlier 3DP methods.

\section{CONCLUSION}

As demonstrated herein, materials suitable for creating microfluidic devices are continuing to increase in quantity and quality. Historically, the choice of materials has been driven by 
considering the resources available and the problem being addressed. For example, if initial prototypes were needed, PDMS might be a useful option. Similarly, if a device

underperformed because of constraints inherent in a planar design, 3DP could be chosen to provide a more favorable architecture. Furthermore, if a device required high pressures or temperatures, an inorganic material might be best suited. Finally, if commercialization was the end goal, thermoplastic or inorganic materials had clear paths to device mass production. In times past, each of these materials possessed clearly defined weaknesses and strengths.

A recent trend is the blurring of these lines of material-specific pros and cons. For example, glass devices have been 3D printed, PDMS production is being scaled up, and wood has been used as a substrate for microfluidic devices. Which emerging and existing technologies will provide the features that designers of microfluidic devices value most? We believe that many applications will benefit from the adoption of more universal materials and fabrication techniques that combine features such as rapid prototyping, suitable mechanical properties, architectural flexibility, high reproducibility, biocompatibility, and an easy path to manufacturing. 3DP technology is rapidly moving toward providing many of these essential capabilities, although some applications, like those requiring high pressures, will likely continue to require the more traditional materials. The ongoing drive to create and improve materials for microfluidic devices should propel the field forward for years to come.

\section{Acknowledgement}

We thank the National Institutes of Health (R01 EB027096 and R01 AI116989) for partial support of this work. HMA acknowledges a scholarship from Taif University, and TRF acknowledges support as a Beckman Scholar from the Arnold and Mabel Beckman Foundation.

\section{Biography}

Jacob B. Nielsen received his B.S. degree in chemical engineering from Brigham Young University (BYU) and is working toward his Ph.D. degree in chemistry at BYU. His current research is focused on development and integration of 3D printed microfluidic devices for preterm birth risk assessment.

Robert L. Hanson obtained his bachelors degree in biochemistry and his masters degree in microbiology from Idaho State University. He is currently a biochemistry Ph.D. candidate at BYU. His current research is focused on using DNA hybridization in microfluidic devices to rapidly detect genes related to drug resistance in medical conditions such as sepsis.

Haifa M. Almughamsi received her B.S degree in biochemistry in Saudi Arabia at King Abdul-Aziz University and a masters degree at Tennessee State University. She is working on her Ph.D. in biochemistry at BYU under the supervision of Dr. Adam T. Woolley developing immunoaffinity monoliths for extraction of preterm birth biomarkers from blood serum in 3D printed microfluidic devices.

Chao Pang obtained a bachelors degree in chemical engineering from Wuhan University of Technology and his masters degree in biochemistry from California State University Fullerton. He is currently a chemistry Ph.D. student at BYU, focusing on developing 
microfluidics with solid-phase extraction and fluorescence labeling technologies for a microfluidic preterm birth risk diagnostic platform.

Taylor R. Fish is an undergraduate research associate and Beckman Scholar at BYU under the direction of Dr. Adam T. Woolley. He will obtain his B.S. degree in Neuroscience from BYU in April 2020. His researched is focused on the development of immunoaffinity monolith extraction assays in 3D-printed microfluidic systems.

Adam T Woolley is University Professor in the Department of Chemistry and Biochemistry at BYU. He graduated summa cum laude with a B.S. in Chemistry from BYU. He received his Ph.D. in Chemistry from the University of California-Berkeley under the direction of Professor Richard Mathies, and his doctoral work was recognized with the Fannie and John Hertz Foundation Thesis Prize. He was a Cancer Research Fund Runyon-Winchell Foundation Postdoctoral Fellow in the group of Professor Charles Lieber at Harvard University. He has been on the faculty in the Department of Chemistry and Biochemistry at BYU for nearly 20 years; he served as Associate Department Chair from 2010-2016 and has been University Professor since 2015. Woolley has received several recognitions, including a Presidential Early Career Award for Scientists and Engineers, the American Chemical Society Division of Analytical Chemistry Award for Young Investigators in Separation Science, and the AES Electrophoresis Society Mid-Career Award. Woolley's current research is concentrated in three general areas: the development of integrated 3D printed microfluidic systems for enhanced biomarker analysis, biotemplated nanofabrication, and the design of simple miniaturized biomolecular assays.

\section{References}

(1). Salafi T; Zeming KK; Zhang Y Lab Chip 2016, 17, 11-33. [PubMed: 27830852]

(2). Du G; Fang Q; den Toonder JM Anal. Chim. Acta 2016, 903, 36-50. [PubMed: 26709297]

(3). Jackson JM; Witek MA; Kamande JW; Soper SA Chem. Soc. Rev 2017, 46, 4245-4280. [PubMed: 28632258]

(4). Trantidou T; Fridden MS; Salehi-Reyhani A; Ces O; Elani Y Lab Chip 2018, 18, 2488-2509. [PubMed: 30066008]

(5). Martinez-Duarte R Electrophoresis 2012, 33, 3110-3132. [PubMed: 22941778]

(6). Gong MM; Sinton D Chem. Rev 2017, 117, 8447-8480. [PubMed: 28627178]

(7). Xia Y; Si J; Li Z Biosens. Bioelectron 2016, 77, 774-789. [PubMed: 26513284]

(8). Yang Y; Noviana E; Nguyen MP; Geiss BJ; Dandy DS; Henry CS Anal. Chem 2017, 89, 71-91. [PubMed: 27936612]

(9). Li H; Steckl AJ Anal. Chem 2019, 91, 352-371. [PubMed: 30257554]

(10). He Y; Wu Y; Fu J.-z.; Gao Q; Qiu J.-j. Electroanalysis 2016, 28, 1658-1678.

(11). Waheed S; Cabot JM; Macdonald NP; Lewis T; Guijt RM; Paull B; Breadmore MC Lab Chip 2016, 16, 1993-2013. [PubMed: 27146365]

(12). Yazdi AA; Popma A; Wong W; Nguyen T; Pan Y; Xu J Microfluid. Nanofluid 2016, 20, 50.

(13). Reyes DR; Iossifidis D; Auroux P-A; Manz A Anal. Chem 2002, 74, 2623-2636. [PubMed: 12090653]

(14). Squires TM; Quake SR Rev. Mod. Phys 2005, 77, 977-1026.

(15). Whitesides GM Nature 2006, 442, 368-373. [PubMed: 16871203]

(16). Terry SC; Jerman JH; Angell JB IEEE Trans. Electron. Dev 1979, 26, 1880-1886.

(17). Nge PN; Rogers CI; Woolley AT Chem. Rev 2013, 113, 2550-2583. [PubMed: 23410114] 
(18). Ren KN; Zhou JH; Wu HK Acc. Chem. Res 2012, 46, 2396-2406.

(19). Grover WH; Skelley AM; Liu CN; Lagally ET; Mathies RA Sens. Actuators B: Chem 2003, 89, 315-323.

(20). Grover WH; Ivester RH; Jensen EC; Mathies RA Lab Chip 2006, 6, 623-631. [PubMed: 16652177]

(21). Qi Z; Xu L; Xu Y; Zhong J; Abedini A; Cheng X; Sinton D Lab Chip 2018, 18, 3872-3880. [PubMed: 30457137]

(22). Li H; Zhang H; Xu Y; Tureckova A; Zahradník P; Chang H; Neuzil P Sens. Actuators B: Chem 2019, 283, 677-684.

(23). Pham NM; Rusch S; Temiz Y; Lovchik RD; Beck HP; Karlen W; Delamarche E Biomed. Microdev 2018, 20, 41.

(24). Yin J; Mou L; Yang M; Zou W; Du C; Zhang W; Jiang X Anal. Chim. Acta 2019, 1060, 133141. [PubMed: 30902327]

(25). Ozkumur AY; Kanik FE; Trueb JT; Yurdakul C; Unlu MS IEEE J. Select. Top. Quant. Electron 2019, 25, 7101207.

(26). Migliozzi D; Nguyen HT; Gijs MAM J. Biomed. Opt 2019, 24, 021204.

(27). Garcia-Cordero E; Bellando F; Zhang J; Wildhaber F; Longo J; Guerin H; Ionescu AM ACS Nano 2018, 12, 12646-12656. [PubMed: 30543395]

(28). Delalat B; Cozzi C; Rasi Ghaemi S; Polito G; Kriel FH; Michl TD; Harding FJ; Priest C; Barillaro G; Voelcker NH Adv. Funct. Mat 2018, 28, 1801825.

(29). Heiland JJ; Geissler D; Piendl SK; Warias R; Belder D Anal. Chem 2019, 91, 6134-6140. [PubMed: 30983329]

(30). Gerhardt RF; Peretzki AJ; Piendl SK; Belder D Anal. Chem 2017, 89, 13030-13037. [PubMed: 29096060]

(31). Jonker D; Veltkamp HW; Sanders RGP; Schlautmann S; Giannasi K; Tiggelaar RM; Gardeniers JGE J. Micromech. Microeng 2019, 29, 035011.

(32). Manz A; Harrison DJ; Verpoorte EMJ; Fettinger JC; Paulus A; Ludi H; Widmer HM J. Chromatogr 1992, 593, 253-258.

(33). Pinheiro KMP; Moreira RC; Rezende KCA; Talhavini M; Logrado LPL; Baio JAF; Lanza MRV; Coltro WKT Electrophoresis 2019, 40, 462-468. [PubMed: 30411387]

(34). Moreira RC; Costa BMC; Marra MC; Santana MHP; Maldaner AO; Botelho ED; Paixao T; Richter EM; Coltro WKT Electrophoresis 2018, 39, 2188-2194. [PubMed: 29947145]

(35). Italia V; Giakoumaki AN; Bonfadini S; Bharadwaj V; Le Phu T; Eaton SM; Ramponi R; Bergamini G; Lanzani G; Criante L Micromachines 2018, 10, 23.

(36). Shan C; Chen F; Yang Q; Jiang Z; Hou X Micromachines 2018, 9, 29.

(37). Calmo R; Lovera A; Stassi S; Chiadò A; Scaiola D; Bosco F; Ricciardi C Sens. Actuators B: Chem 2019, 283, 298-303.

(38). Kazoe Y; Pihosh Y; Takahashi H; Ohyama T; Sano H; Morikawa K; Mawatari K; Kitamori T Lab Chip 2019, 19, 1686-1694. [PubMed: 30942790]

(39). Gal-Or E; Gershoni Y; Scotti G; Nilsson SME; Saarinen J; Jokinen V; Strachan CJ; Boije af Gennäs G; Yli-Kauhaluoma J; Kotiaho T Anal. Meth 2019, 11, 1802-1810.

(40). Kopparthy VL; Crews ND J. Microelectromech. Syst 2018, 27, 434-439.

(41). Hirama H; Satoh T; Sugiura S; Shin K; Onuki-Nagasaki R; Kanamori T; Inoue TJ Biosci. Bioeng 2019, 127, 641-646.

(42). Fakunle ES; Fritsch I Anal. Bioanal. Chem 2010, 398, 2605-2615. [PubMed: 20803005]

(43). Berenguel-Alonso M; Ortiz-Gómez I; Fernández B; Couceiro P; Alonso-Chamarro J; CapitánVallvey LF; Salinas-Castillo A; Puyol M Sens. Actuators B: Chem 2019, 296, DOI: 10.1016/ j.snb.2019.1005.1090.

(44). Díaz Lantada A; de Blas Romero A; Schwentenwein M; Jellinek C; Homa J; García-Ruíz JP J. Adv. Manufact. Tech 2017, 93, 3371-3381.

(45). Lokensgard E Industrial plastics : theory and applications, 6th edition. ed.; Cengage Learning: Australia ; Boston, MA, 2017, p xv, 512 pages. 
(46). Agarwal M; Wible E; Ramir T; Altun S; Viana G; Evans C; Lukic H; Megremis S; Atsawasuwan P Angle Orthod. 2018, 88, 355-362. [PubMed: 29509024]

(47). Ebnalwaled AA; Thabet A Syn. Met 2016, 220, 374-383.

(48). Klein R Laser welding of plastics; Wiley-VCH: Weinheim, 2012, p 251.

(49). Beich WS; Turner N In Poly. Opt. Des. Fab. Mat, Krevor DH, Ed.; SPIE: Rochester, NY, 2010, p 778805 .

(50). Gencturk E; Mutlu S; Ulgen KO Biomicrofluidics 2017, 11, 051502. [PubMed: 29152025]

(51). Tsao CW Micromachines 2016, 7, 225.

(52). Wu Z; Chen X; Wu Z; Zhang Q; Gao Q Microsys. Tech 2019, 25, 1251-1256.

(53). Yin Z; Wang W Microfluid. Nanofluid 2018, 22, 99.

(54). Lin TY; Pfeiffer TT; Lillehoj PB RSC Adv. 2017, 7, 37374-37379. [PubMed: 29308188]

(55). Cheng Z; Gu Y; Li S; Wang Y; Chen H; Cheng J; Liu P Sens. Actuators B: Chem 2017, 252, 785-793.

(56). Ganser P; Baum C; Chargin D; Sauer-Budge AF; Sharon A Biomed Microdev. 2018, $20,24$.

(57). Su S; Jing G; Zhang M; Liu B; Zhu X; Wang B; Fu M; Zhu L; Cheng J; Guo Y Sens. Actuators B: Chem 2019, 282, 60-68.

(58). Fan Y; Liu S; Zhang Y Microsys. Tech 2018, 24, 1659-1665.

(59). Faghih MM; Sharp MK Microsys. Tech 2019, 25, 3547-3558.

(60). Ling N; Lee JS; Lee NY Sens. Actuators A: Phys 2017, 265, 168-173.

(61). Liang C; Meng F; Li J; Liu CJ Mater. Proc. Tech 2018, 252, 25-33.

(62). Voicu D; Lestari G; Wang Y; DeBono M; Seo M; Cho S; Kumacheva E RSC Adv. 2017, 7, 2884 2889.

(63). Sun H; Chan CW; Wang Y; Yao X; Mu X; Lu X; Zhou J; Cai Z; Ren K Lab Chip 2019, 19, 2915-2924. [PubMed: 31369010]

(64). Liang F; Qiao Y; Duan M; Ju A; Lu N; Li J; Tu J; Lu Z RSC Adv. 2018, 8, 8732-8738.

(65). Fan Y; Liu S; He J; Gao K; Zhang Y Microsys. Tech 2018, 24, 2847-2852.

(66). Ku X; Zhuang G; Li G Microfluid. Nanofluid 2018, 22, 17.

(67). Aeinehvand MM; Weber L; Jimenez M; Palermo A; Bauer M; Loeffler FF; Ibrahim F; Breitling F; Korvink J; Madou M; Mager D; Martinez-Chapa SO Lab Chip 2019, 19, 1090-1100. [PubMed: 30785443]

(68). Lauri J; Liedert C; Kokkonen A; Fabritius T Mat. Res. Exp 2019, 6, 075333.

(69). Lee UN; Su X; Guckenberger DJ; Dostie AM; Zhang T; Berthier E; Theberge AB Lab Chip 2018, 18, 496-504. [PubMed: 29309079]

(70). Lee TY; Han K; Barrett DO; Park S; Soper SA; Murphy MC Sens. Actuators B: Chem 2018, 254, 1249-1258. [PubMed: 29531428]

(71). Giménez-Gómez P; Fernández-Sánchez C; Baldi A ACS Omega 2019, 4, 6192-6198.

(72). Ghosh S; Kamalakshakurup G; Lee AP; Ahn CH J. Micromech. Microeng 2019, 29, 055009.

(73). Sahore V; Doonan SR; Bailey RC Anal. Meth 2018, 10, 4264-4274.

(74). Szymborski T; Jankowski P; Garstecki P Sens. Actuators B: Chem 2018, 255, 2274-2281.

(75). Wouters B; Pirok BWJ; Soulis D; Garmendia Perticarini RC; Fokker S; van den Hurk RS; Skolimowski M; Peters RAH; Schoenmakers PJ Anal. Chim. Acta 2019, 1053, 62-69. [PubMed: 30712570]

(76). Lachaux J; Alcaine C; Gomez-Escoda B; Perrault CM; Duplan DO; Wu PJ; Ochoa I; Fernandez L; Mercier O; Coudreuse D; Roy E Lab Chip 2017, 17, 2581-2594. [PubMed: 28656191]

(77). Perez-Toralla K; Pereiro I; Garrigou S; Di Federico F; Proudhon C; Bidard F-C; Viovy J-L; Taly V; Descroix S Sens. Actuators B: Chem 2019, 286, 533-539.

(78). Campos CDM; Gamage SST; Jackson JM; Witek MA; Park DS; Murphy MC; Godwin AK; Soper SA Lab Chip 2018, 18, 3459-3470. [PubMed: 30339164]

(79). Aoyama S; Akiyama Y; Monden K; Yamada M; Seki M Analyst 2019, 144, 1519-1526. [PubMed: 30539188]

(80). Lee KK; Kim MO; Choi SJ Pharm. Biomed. Anal 2019, 162, 28-33. 
(81). Odabasi IE; Gencturk E; Puza S; Mutlu S; Ulgen KO Biomed Microdev. 2018, $20,57$.

(82). Moore N; Doty D; Zielstorff M; Kariv I; Moy LY; Gimbel A; Chevillet JR; Lowry N; Santos J; Mott V; Kratchman L; Lau T; Addona G; Chen H; Borenstein JT Lab Chip 2018, 18, 1844-1858. [PubMed: 29796561]

(83). Trinh KTL; Minh Chon N; Lee NY Anal. Meth 2018, 10, 5071-5077.

(84). Knob R; Hanson RL; Tateoka OB; Wood RL; Guerrero-Arguero I; Robison RA; Pitt WG; Woolley AT J. Chromatogr. A 2018, 1562, 12-18. [PubMed: 29859687]

(85). Knob R; Nelson DB; Robison RA; Woolley AT J. Chromatogr. A 2017, 1523, 309-315. [PubMed: 28734608]

(86). Wan AMD; Devadas D; Young EWK Sens. Actuators B: Chem 2017, 253, 738-744.

(87). Andar A; Hasan MS; Srinivasan V; Al-Adhami M; Gutierrez E; Burgenson D; Ge X; Tolosa L; Kostov Y; Rao G Anal. Chem 2019, 91, 11004-11012. [PubMed: 31361950]

(88). Sia SK; Whitesides GM Electrophoresis 2003, 24, 3563-3576. [PubMed: 14613181]

(89). Unger MA; Chou H; Thorsen T; Scherer A; Quake S Science 2000, 288, 113-116. [PubMed: 10753110]

(90). Song H; Ismagilov RF J. Am. Chem. Soc 2003, 125, 14613-14619. [PubMed: 14624612]

(91). de Jong J; Lammertink RG; Wessling M Lab Chip 2006, 6, 1125-1139. [PubMed: 16929391]

(92). McDonald JC; Duffy DC; Anderson JR; Chiu DT; Wu H; Schueller OJ; Whitesides GM Electrophoresis 2000, 21, 27-40. [PubMed: 10634468]

(93). Hiltunen J; Liedert C; Hiltunen M; Huttunen OH; Hiitola-Keinanen J; Aikio S; Harjanne M; Kurkinen M; Hakalahti L; Lee LP Lab Chip 2018, 18, 1552-1559. [PubMed: 29708259]

(94). Olmos CM; Vaca A; Rosero G; Peñaherrera A; Perez C; de Sá Carneiro I; Vizuete K; Arroyo CR; Debut A; Pérez MS; Cumbal L; Lerner B Sens. Actuators B: Chem 2019, 288, 742-748.

(95). Tang W; Fan N; Yang J; Li Z; Zhu L; Jiang D; Shi J; Xiang N Microfluid. Nanofluid 2019, 23, 42.

(96). Goh WH; Hashimoto M Micromachines 2018, 9, 523.

(97). Qiu J; Gao Q; Zhao H; Fu J; He Y ACS Biomat. Sci. Eng 2017, 3, 2606-2616.

(98). Alfadhel A; Ouyang J; Mahajan CG; Forouzandeh F; Cormier D; Borkholder DA Mater. Des 2018, 150, 182-187. [PubMed: 30364619]

(99). Speller NC; Morbioli GG; Cato ME; Cantrell TP; Leydon EM; Schmidt BE; Stockton AM Sens. Actuators B: Chem 2019, 291, 250-256.

(100). Lin Y; Gao C; Gritsenko D; Zhou R; Xu J Microfluid. Nanofluid 2018, 22, 97.

(101). Adiraj Iyer M; Eddington DT Lab Chip 2019, 19, 574-579. [PubMed: 30681692]

(102). Thompson AJ; Ma LJ; Plegue TJ; Potkay JA IEEE Trans. Biomed. Eng 2019, 66, 1082-1093. [PubMed: 30139043]

(103). Majhy B; Iqbal R; Gaikwad R; Sen AK Microfluid. Nanofluid 2018, 22, 116.

(104). Lolsberg J; Linkhorst J; Cinar A; Jans A; Kuehne AJC; Wessling M Lab Chip 2018, 18, 13411348. [PubMed: 29619449]

(105). Rambach RW; Linder K; Heymann M; Franke T Lab Chip 2017, 17, 3422-3430. [PubMed: 28792054]

(106). Liu C-F; Wang M-H; Jang L-S Sens. Actuators B: Chem 2018, 263, 129-136.

(107). Singh C; Ali MA; Reddy V; Singh D; Kim CG; Sumana G; Malhotra BD Sens. Actuators B: Chem 2018, 255, 2495-2503.

(108). Kamat V; Pandey S; Paknikar K; Bodas D Biosens. Bioelectron 2018, 99, 62-69. [PubMed: 28738229]

(109). Machado JMD; Soares RRG; Chu V; Conde JP Biosens. Bioelectron 2018, 99, 40-46. [PubMed: 28735045]

(110). Kaur G; Tomar M; Gupta V Sens. Actuators B: Chem 2018, 261, 460-466.

(111). Perrier R; Pirog A; Jaffredo M; Gaitan J; Catargi B; Renaud S; Raoux M; Lang J Biosens. Bioelectron 2018, 117, 253-259. [PubMed: 29909196]

(112). Srisa-Art M; Noblitt SD; Krummel AT; Henry CS Anal. Chim. Acta 2018, 1021, 95-102. [PubMed: 29681289] 
(113). Sahore V; Sonker M; Nielsen AV; Knob R; Kumar S; Woolley AT Anal. Bioanal. Chem 2018, 410, 933-941. [PubMed: 28799040]

(114). Ma YD; Chang WH; Luo K; Wang CH; Liu SY; Yen WH; Lee GB Biosens. Bioelectron 2018, 99, 547-554. [PubMed: 28823979]

(115). Ning Y; Cui X; Yang C; Jing F; Bian X; Yi L; Li G Anal. Chim. Acta 2019, 1055, 65-73. [PubMed: 30782371]

(116). Choi CH; Lee H; Weitz DA ACS Appl. Mater. Interfaces 2018, 10, 3170-3174. [PubMed: 29336541]

(117). Tirandazi P; Hidrovo CH Sens. Actuators B: Chem 2018, 267, 279-293.

(118). Akhtar M; van den Driesche S; Bödecker A; Vellekoop MJ Sens. Actuators B: Chem 2018, 255 , 3576-3584.

(119). Sun Y; Cai B; Wei X; Wang Z; Rao L; Meng QF; Liao Q; Liu W; Guo S; Zhao X Electrophoresis 2019, 40, 961-968. [PubMed: 30155963]

(120). Raveshi MR; Agnihotri SN; Sesen M; Bhardwaj R; Neild A Sens. Actuators B: Chem 2019, 292, 233-240.

(121). Li Z; Dey P; Kim S Sens. Actuators B: Chem 2019, 296, DOI: 10.1016/j.snb.2019.126692.

(122). Dettinger P; Frank T; Etzrodt M; Ahmed N; Reimann A; Trenzinger C; Loeffler D; Kokkaliaris KD; Schroeder T; Tay S Anal. Chem 2018, 90, 10695-10700. [PubMed: 30059208]

(123). Wang Y; Zhu J; Chen P; Hu L; Feng X; Du W; Liu BF Talanta 2019, 192, 431-438. [PubMed: 30348414]

(124). Li R; Zhang X; Lv X; Geng L; Li Y; Qin K; Deng Y Anal. Biochem 2017, 539, 48-53. [PubMed: 29031457]

(125). Papadimitriou VA; Segerink LI; van den Berg A; Eijkel JCT Anal. Chim. Acta 2018, 1000, 232238. [PubMed: 29289315]

(126). Lee J; Estlack Z; Somaweera H; Wang X; Lacerda CMR; Kim J Lab Chip 2018, 18, 2946-2954. [PubMed: 30123895]

(127). Wei X; Hao Y; Huang X; Hu Y; Xiong B Talanta 2019, 198, 404-411. [PubMed: 30876579]

(128). Xu T; Fu H; Li Y; Chen X; Cheuk W; Li C; Zou H; Yue W; Au S; Wang Y; Yang M Sens. Actuators B: Chem 2019, 293, 224-234.

(129). Guler MT; Beyazkilic P; Elbuken C Sens. Actuators A: Phys 2017, 265, 224-230.

(130). Bunge F; van den Driesche S; Vellekoop MJ Biomed. Microdev 2018, 20, 98.

(131). Chun H Electrophoresis 2018, 39, 2181-2187. [PubMed: 29896779]

(132). Bandara GC; Heist CA; Remcho VT Talanta 2018, 176, 589-594. [PubMed: 28917794]

(133). Malankowska M; Julian I; Pellejero I; Rho HS; Schlautmann S; Tiggelaar RM; Pina MP; Gardeniers HJGE; Mallada R Sens. Actuators B: Chem 2019, 288, 414-424.

(134). Im SB; Uddin MJ; Jin GJ; Shim JS Lab Chip 2018, 18, 1310-1319. [PubMed: 29619470]

(135). Lee S; Kim H; Lee W; Kim J Micro. Nano. Syst. Lett 2018, 6, 1.

(136). Zhang J; Su X; Xu J; Wang J; Zeng J; Li C; Chen W; Li T; Min X; Zhang D; Zhang S; Ge S; Zhang J; Xia N Biomicrofluidics 2019, 13, 034102. [PubMed: 31123534]

(137). Pramanik S; Suzuki H Microfluid. Nanofluid 2019, 23, 19.

(138). Liu B; Yang J; Yang J; Li D; Gao G; Wang Y Microsyst. Technol 2019, 25, 3969-3975.

(139). Yang SH; Park J; Youn JR; Song YS Lab Chip 2018, 18, 2865-2872. [PubMed: 30105331]

(140). Pinto IF; Santos DR; Soares RRG; Aires-Barros MR; Chu V; Azevedo AM; Conde JP Sens. Actuators B: Chem 2018, 255, 3636-3646.

(141). Ehrenhofer A; Elstner M; Wallmersperger T Sensors and Actuators B: Chemical 2018, 255 , 1343-1353.

(142). Simon D; Obst F; Haefner S; Heroldt T; Peiter M; Simon F; Richter A; Voit B; Appelhans D React. Chem. Eng 2019, 4, 67-77.

(143). Berry SB; Zhang T; Day JH; Su X; Wilson IZ; Berthier E; Theberge AB Lab Chip 2017, 17, 4253-4264. [PubMed: 29164190]

(144). Brassard D; Geissler M; Descarreaux M; Tremblay D; Daoud J; Clime L; Mounier M; Charlebois D; Veres T Lab Chip 2019, 19, 1941-1952. [PubMed: 30997461] 
(145). Lei Z; Xie D; Mbogba MK; Chen Z; Tian C; Xu L; Zhao G Lab Chip 2019, 19, 1929-1940. [PubMed: 31038148]

(146). Alsharhan AT; Acevedo R; Warren R; Sochol RD Lab Chip 2019, 19, 2799-2810. [PubMed: 31334525]

(147). Bressan LP; Adamo CB; Quero RF; de Jesus DP; da Silva JAF Anal. Meth 2019, 11, 1014 1020.

(148). Lynh HD; Pin-Chuan C Sens. Actuators A: Phys 2018, 280, 350-358.

(149). Nelson MD; Ramkumar N; Gale BK J. Micromech. Microeng 2019, 29, 095010.

(150). Salentijn GI; Oomen PE; Grajewski M; Verpoorte E Anal. Chem 2017, 89, 7053-7061. [PubMed: 28628294]

(151). Romanov V; Samuel R; Chaharlang M; Jafek AR; Frost A; Gale BK Anal. Chem 2018, 90, 10450-10456. [PubMed: 30071717]

(152). Goh WH; Hashimoto M Macromol. Mat. Eng 2018, 303, 1700484.

(153). Bressan LP; Robles-Najar J; Adamo CB; Quero RF; Costa BMC; de Jesus DP; da Silva JAF Microchem. J 2019, 146, 1083-1089.

(154). Duarte LC; Chagas CLS; Ribeiro LEB; Coltro WKT Sens. Actuators B: Chem 2017, 251, 427432.

(155). Pol R; Céspedes F; Gabriel D; Baeza M Sens. Actuators B: Chem 2019, 290, 364-370.

(156). Singh M; Tong Y; Webster K; Cesewski E; Haring AP; Laheri S; Carswell B; O’Brien TJ; Aardema CH; Senger RS; Robertson JL; Johnson BN Lab Chip 2017, 17, 2561-2571. [PubMed: 28632265]

(157). Bhattacharjee N; Parra-Cabrera C; Kim YT; Kuo AP; Folch A Adv. Mater 2018, 30, e1800001. [PubMed: 29656459]

(158). Kotz F; Risch P; Helmer D; Rapp BE Micromachines 2018, 9, 155.

(159). Santangelo MF; Libertino S; Turner APF; Filippini D; Mak WC Biosens. Bioelectron 2018, 99, 464-470. [PubMed: 28820988]

(160). Beckwith AL; Borenstein JT; Velasquez-Garcia LF J. Microelectromech. Sys 2018, 27, 10091022.

(161). Beauchamp MJ; Gong H; Woolley AT; Nordin GP Micromachines 2018, 9, 326.

(162). Gong H; Bickham BP; Woolley AT; Nordin GP Lab Chip 2017, 17, 2899-2909. [PubMed: 28726927]

(163). Beauchamp MJ; Nielsen AV; Gong H; Nordin GP; Woolley AT Anal. Chem 2019, 91, 74187425. [PubMed: 31056901]

(164). Parker EK; Nielsen AV; Beauchamp MJ; Almughamsi HM; Nielsen JB; Sonker M; Gong H; Nordin GP; Woolley AT Anal. Bioanal. Chem 2019, 411, 5405-5413. [PubMed: 30382326]

(165). Gong H; Woolley AT; Nordin GP Lab Chip 2018, 18, 639-647. [PubMed: 29355276]

(166). Castiaux AD; Pinger CW; Hayter EA; Bunn ME; Martin RS; Spence DM Anal. Chem 2019, 91, 6910-6917. [PubMed: 31035747]

(167). Enders A; Siller IG; Urmann K; Hoffmann MR; Bahnemann J Small 2019, 15, e1804326. [PubMed: 30548194]

(168). Walczak R; Adamski K; Kubicki W Sens. Actuators B: Chem 2018, 261, 474-480.

(169). Walczak R; Adamski K; Kubicki WJ Micromech. Microeng 2019, 29, 057001.

(170). Munshi AS; Chen C; Townsend AD; Martin RS Anal. Meth 2018, 10, 3364-3374.

(171). Ji Q; Zhang JM; Liu Y; Li X; Lv P; Jin D; Duan H Sci. Rep 2018, 8, 4791. [PubMed: 29556013]

(172). Macdonald NP; Cabot JM; Smejkal P; Guijt RM; Paull B; Breadmore MC Anal. Chem 2017, 89, 3858-3866. [PubMed: 28281349]

(173). Zeraatkar M; Filippini D; Percoco G Micromachines 2019, 10, 298.

(174). Grosche M; Zoheir AE; Stegmaier J; Mikut R; Mager D; Korvink JG; Rabe KS; Niemeyer CM Small 2019, 15, e1901956. [PubMed: 31305015] 

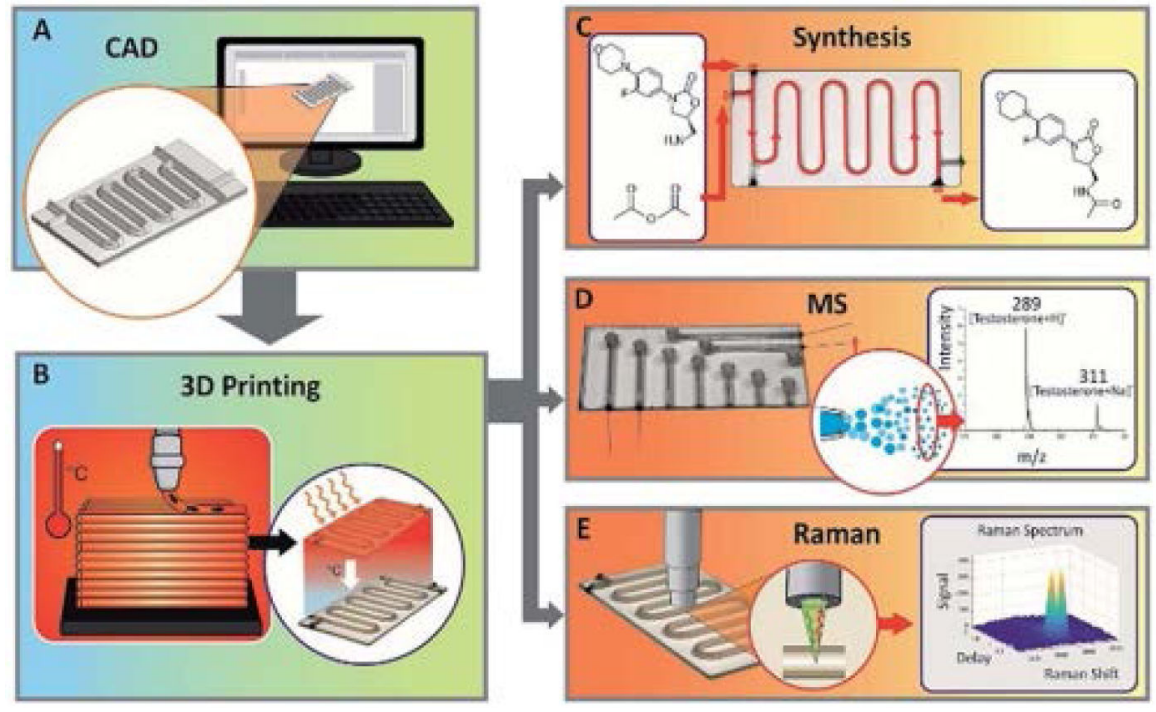

Figure 1.

Glass microfluidic device 3DP. ${ }^{39}$ (A) Computer-aided design. (B) 3DP devices for (C) synthesis of molecules, (D) combining with MS, or (E) analyzing with Raman spectroscopy. Reproduced from Gal-Or, E.; Gershoni, Y.; Scotti, G.; Nilsson, S. M. E.; Saarinen, J.; Jokinen, V.; Strachan, C. J.; Boije af Gennäs, G.; Yli-Kauhaluoma, J.; Kotiaho, T. Anal. Meth. 2019, 11, 1802-1810 (ref 39), with permission of The Royal Society of Chemistry. 


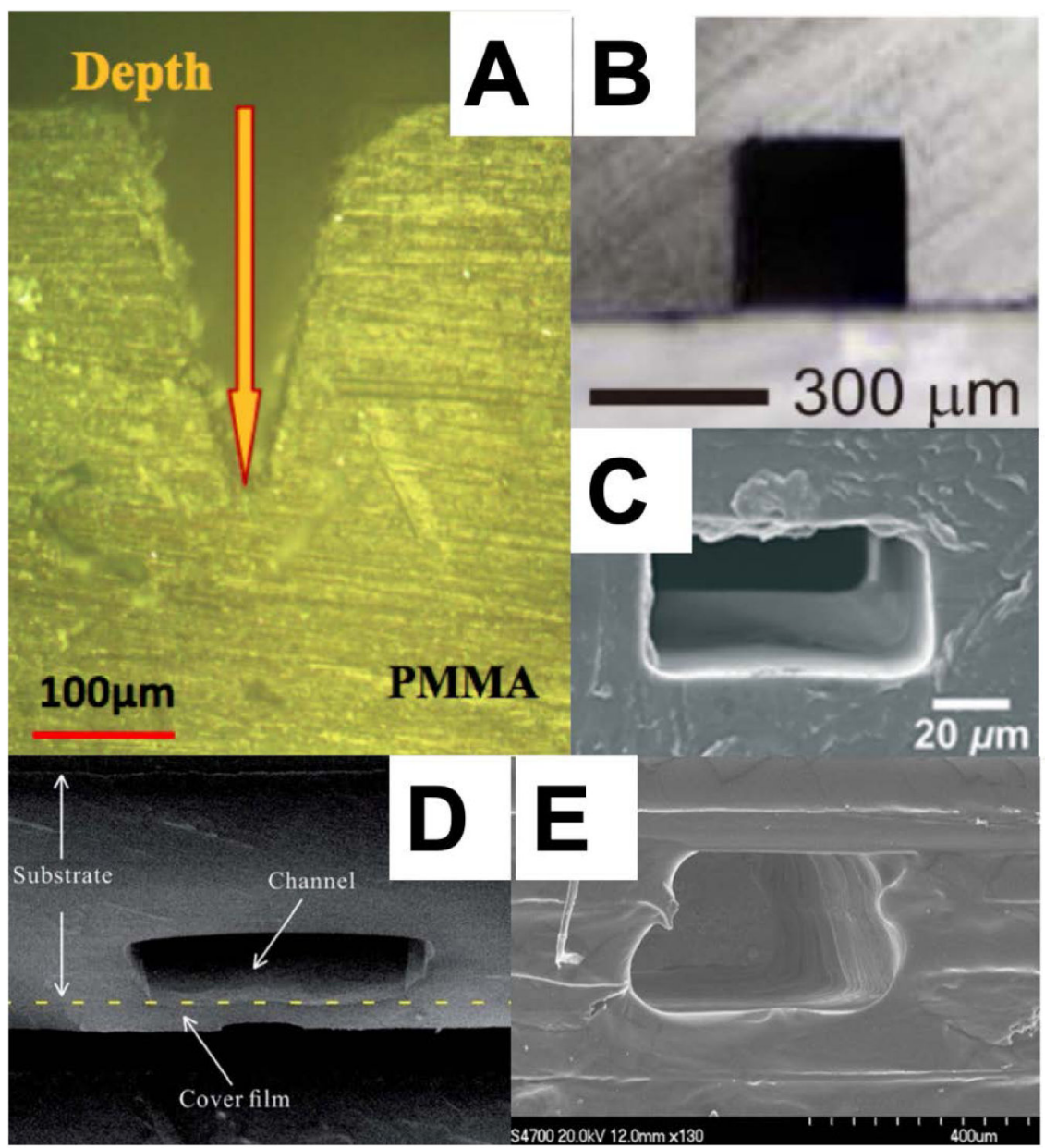

Figure 2.

Micromachined thermoplastics formed using various methods that yield differing degrees of channel roughness. (A) Laser ablated PMMA. ${ }^{52}$ Reprinted by permission from Springer, Microsys. Tech., Experimental Study of Fabricating a Four-Layers Cantor Fractal Microfluidic Chip by $\mathrm{CO}_{2}$ Laser System, Wu, Z.; Chen, X.; Wu, Z.; Zhang, Q.; Gao, Q. Vol. 25, pp. 1251-1256 (ref 52). Copyright 2019. (B) Solvent-assisted hardening of PMMA before sealing. ${ }^{60}$ Reprinted from Sens. Actuators A: Phys., Vol. 265, Ling, N.; Lee, J. S.; Lee, N. Y. Solvent-Assisted Low-Temperature and Low-Pressure Poly(methylmethacrylate) Bonding Coupled with Selective Microchannel Hydrophobic Coating for Reliable Sealing, pp. 168-173 (ref 60). Copyright 2017, with permission from Elsevier. (C) PDMS-embossed, hot-press-sealed PP. ${ }^{63}$ Reproduced from Sun, H.; Chan, C. W.; Wang, Y.; Yao, X.; Mu, X.; Lu, X.; Zhou, J.; Cai, Z.; Ren, K. Lab Chip 2019, 19, 2915-2924 (ref 63), with permission of The Royal Society of Chemistry. (D) Hot embossing with fast copper film assisted heating. 64 Reproduced from Liang, F.; Qiao, Y.; Duan, M.; Ju, A.; Lu, N.; Li, J.; Tu, J.; Lu, Z. RSC Adv. 2018, 8, 8732-8738 (ref 64), with permission of The Royal Society of Chemistry. (E) Multiple layers of PSAs. ${ }^{65}$ Reprinted by permission from Springer, Microsys. Tech., Rapid Prototyping of Flexible Multilayer Microfluidic Devices using Polyester Sealing Film, Fan, Y.; Liu, S.; He, J.; Gao, K.; Zhang, Y. Vol. 24, pp. 2847-2852 (ref 65). Copyright 2018. 

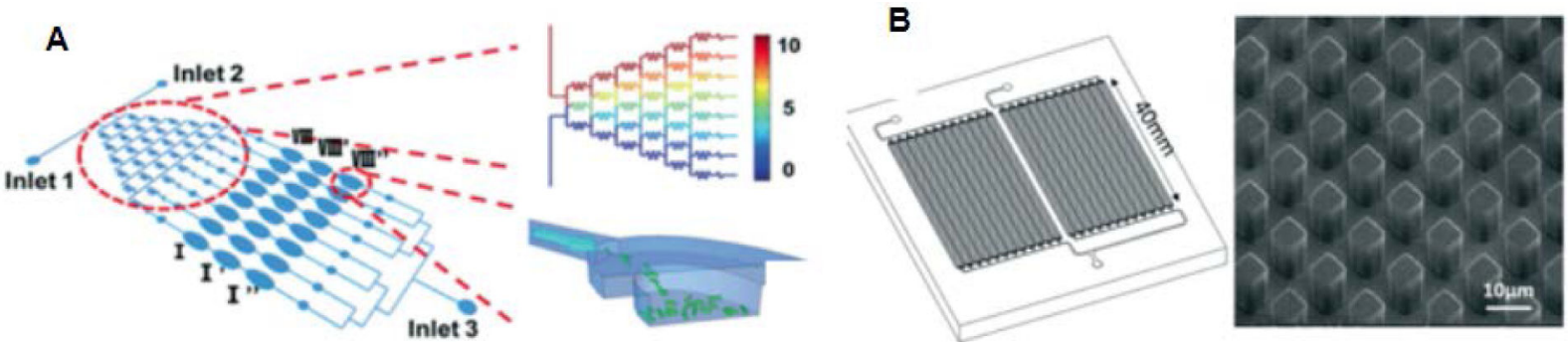

Figure 3.

Rigid polymer microfluidic devices for bioanalytical applications. (A) Antimicrobial susceptibility testing device made from PP. A concentration gradient resulting from the design of the wells made in series. ${ }^{63}$ Reproduced from Sun, H.; Chan, C. W.; Wang, Y.; Yao, X.; Mu, X.; Lu, X.; Zhou, J.; Cai, Z.; Ren, K. Lab Chip 2019, 19, 2915-2924 (ref 63), with permission of The Royal Society of Chemistry. (B) A PC and COC device that was modified with UV light to allow solid-phase extraction of DNA. ${ }^{78}$ Reproduced from Campos, C. D. M.; Gamage, S. S. T.; Jackson, J. M.; Witek, M. A.; Park, D. S.; Murphy, M. C.; Godwin, A. K.; Soper, S. A. Lab Chip 2018, 18, 3459-3470 (ref 78), with permission of The Royal Society of Chemistry. 

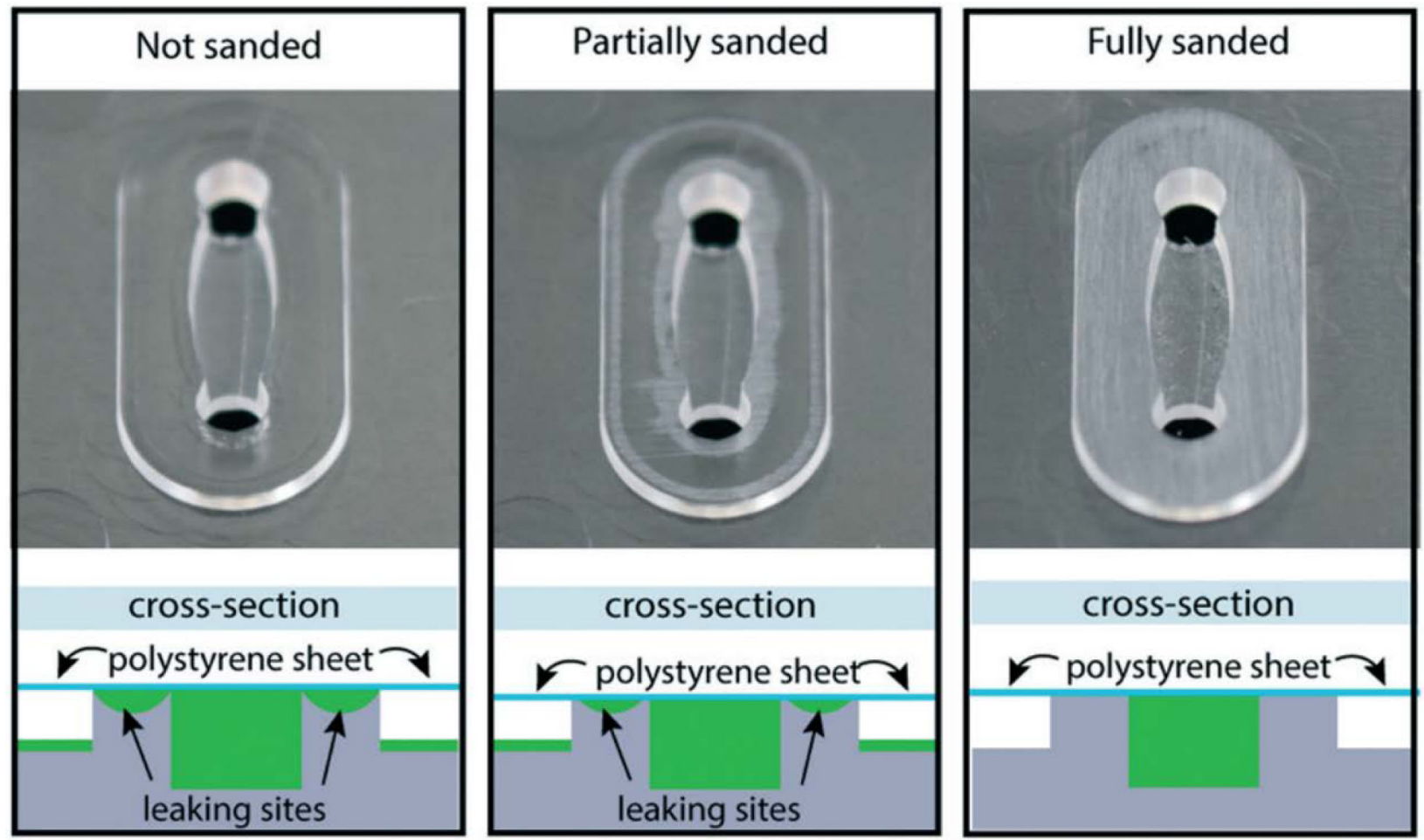

Figure 4:

Injection molding can produce many identical copies at large scale, but unique considerations must be addressed to ensure that devices seal correctly; channel edge surfaces sanded to create an even plane sealed best. ${ }^{69}$ Reproduced from Lee, U. N.; Su, X.;

Guckenberger, D. J.; Dostie, A. M.; Zhang, T.; Berthier, E.; Theberge, A. B. Lab Chip 2018, 18, 496-504 (ref 69), with permission of The Royal Society of Chemistry. 


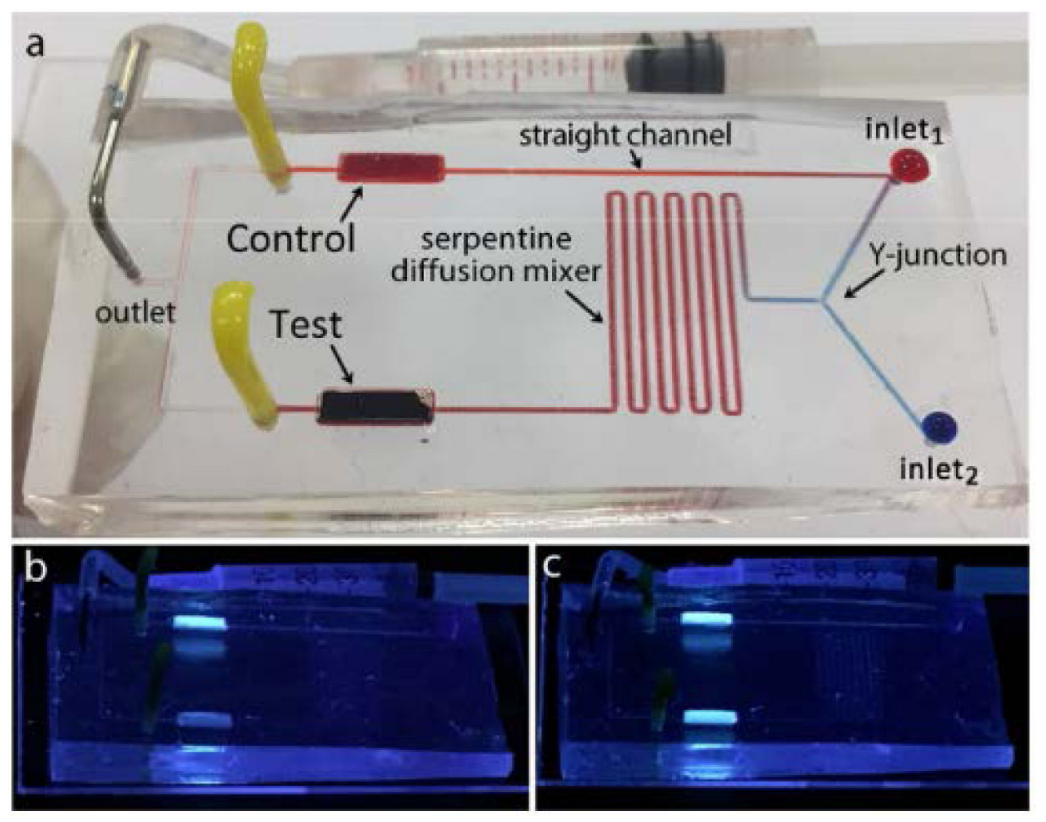

Figure 5.

Plug microvalve integrated device for rapid and portable qualitative TNT detection. ${ }^{129}$ (a) Device photograph where fluorescent silica nanoparticle and TNT solutions were introduced by the two inlets. Mixing of TNT and nanoparticle solutions leads to fluorescence quenching in the test channel. (b) Device tested with TNT solution under $366 \mathrm{~nm}$ excitation. (c) Control assay run with water. Reprinted from Sens. Actuators A: Phys., Vol. 265, Guler, M. T.;

Beyazkilic, P.; Elbuken, C. A Versatile Plug Microvalve for Microfluidic Applications, pp. 224-230 (ref 129). Copyright 2017, with permission from Elsevier. 

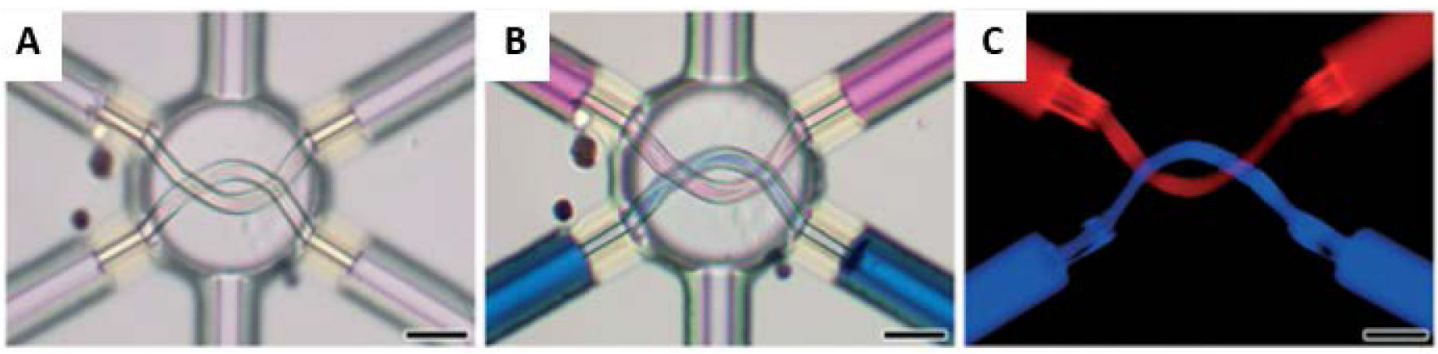

Figure 6.

Results for interweaving COC 3D microstructures. ${ }^{146}$ Scale bars are $50 \mu \mathrm{m}$. Device photographs (A) prior to and (B) after microfluidic loading of rhodamine B-labeled fluid (pink) and methylene blue-labeled fluid (blue). (C) Fluorescence micrographs of the microvessel structures filled with distinctly labeled fluids. Reproduced from Alsharhan, A. T.; Acevedo, R.; Warren, R.; Sochol, R. D. Lab Chip 2019, 19, 2799-2810 (ref 146), with permission of The Royal Society of Chemistry. 

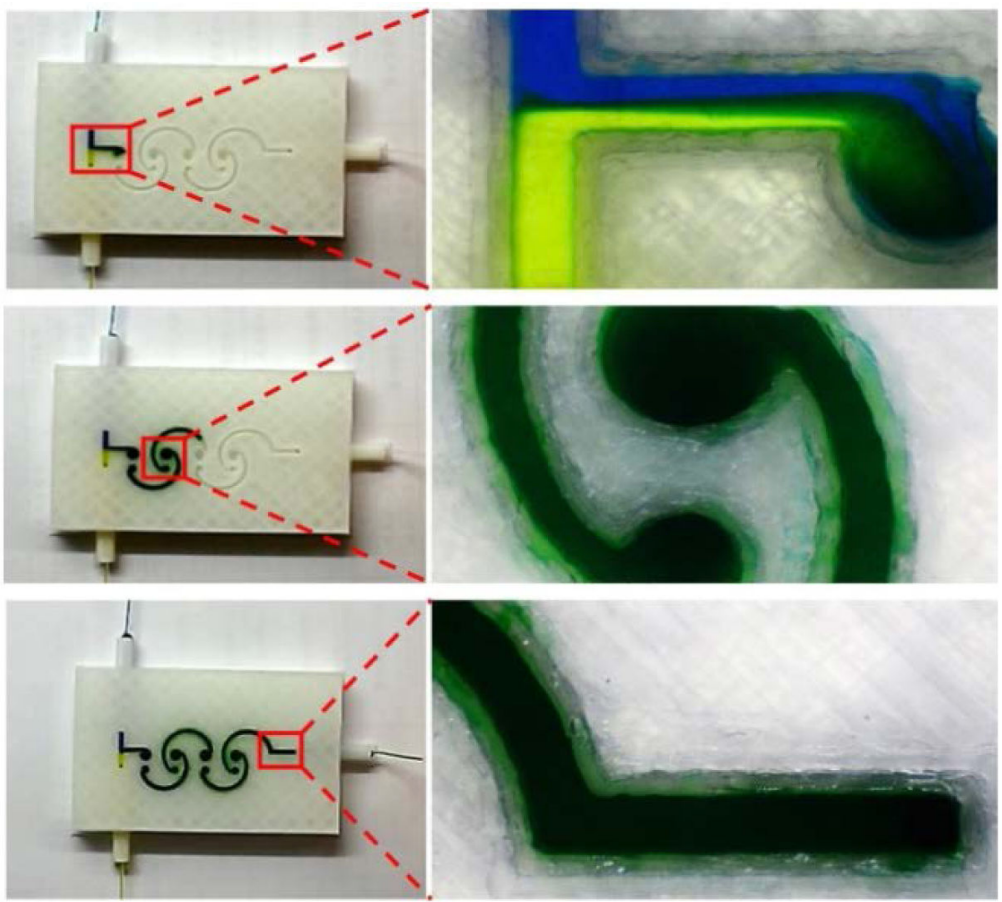

Figure 7.

An ethanol-based, solvent-assisted bonding method was used to achieve strong bonding between PLA and PMMA to generate optically transparent FDM microfluidic devices. ${ }^{148}$ Reprinted from Sens. Actuators A: Phys., Vol. 280, Lynh, H.; Pin-Chuan, C. Novel Solvent Bonding Method for Creation of a Three-Dimensional, Non-Planar, Hybrid PLA/PMMA Microfluidic Chip, pp. 350-358 (ref 148). Copyright 2018, with permission from Elsevier. 
a

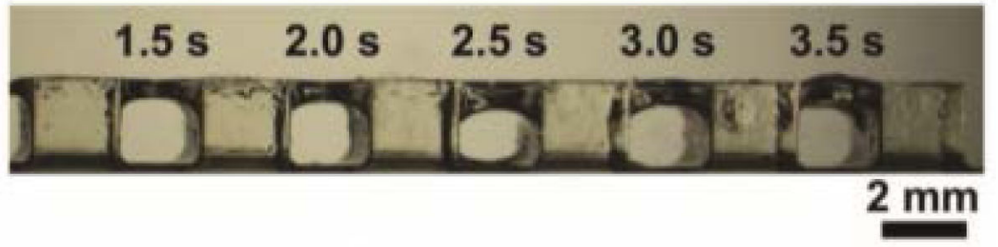

b
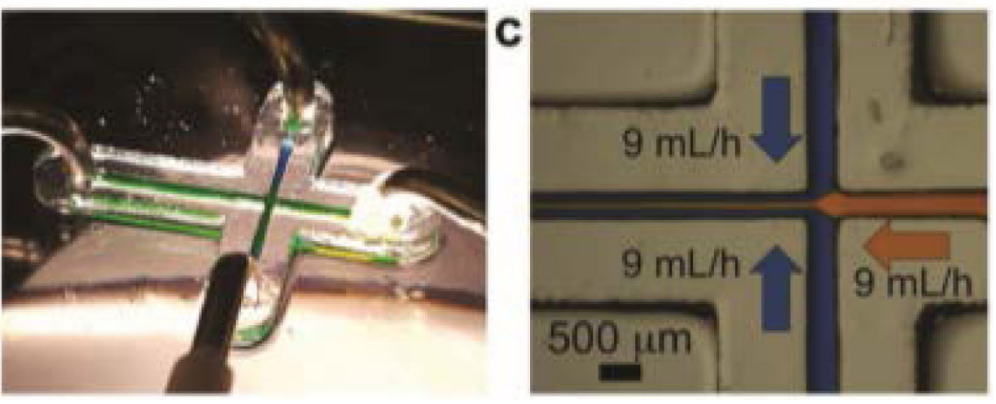

Figure 8.

3D printed PDMS (a) bridges at different exposure times, (b) fluidic device with a cross section of $500 \times 500 \mu^{2}$, and (c) blue and yellow dye flowing through the channels of the device in (b). ${ }^{157}$ Reproduced from Desktop-Stereolithography 3D-Printing of a Poly(dimethylsiloxane)-Based Material with Sylgard-184 Properties, Bhattacharjee, N.; Parra-Cabrera, C.; Kim, Y. T.; Kuo, A. P.; Folch, A. Adv. Mater., Vol. 30, Issue 22 (ref 157). Copyright 2018 Wiley. 
Table 1.

Select properties of rigid polymers commonly used in microfluidics research.

\begin{tabular}{cccc}
\hline & $\mathbf{T}_{\mathbf{g}}\left({ }^{\circ} \mathbf{C}\right)$ & $\mathbf{T}_{\mathbf{m}}\left({ }^{\circ} \mathbf{C}\right)$ & $\mathbf{\%} \mathbf{T}$ (visible) \\
\hline Widely Used & & & \\
Polymethyl Methacrylate (PMMA) & 104 & 180 & 92 \\
Polystyrene (PS) & 97 & 160 & $87-92$ \\
Polycarbonate (PC) & 145 & 240 & $85-91$ \\
Cyclic Olefin Copolymer (COC) & $80-180$ & $*$ & 92 \\
Moderately Used & & & \\
Polypropylene (PP) & -18 & $160-208$ & 60 \\
Polyurethane (PU) & -30 & 140 & $90-95$ \\
Polytetrafluoroethylene (PTFE) & -20 & 327 & Generally opaque \\
Polyvinylchloride (PVC) & 80 & 175 & 80 \\
\hline
\end{tabular}

${ }^{*} \mathrm{~T}_{\mathrm{g}}$ and $\mathrm{T}_{\mathrm{m}}$ vary depending on copolymer used. 
Table 2.

3DP materials, printers, advantages, and applications.

\begin{tabular}{|c|c|c|c|c|}
\hline $\begin{array}{l}\text { Printing } \\
\text { Technology }\end{array}$ & Material & $\begin{array}{l}\text { Printer } \\
\text { Model }\end{array}$ & Advantages & Applications \\
\hline \multirow[t]{5}{*}{ FDM } & ABS & Prusa MovtecH & $\begin{array}{l}\text { Biocompatible, integrates well with } \\
\text { electrodes }\end{array}$ & C4D measurements of microdroplets ${ }^{154}$ \\
\hline & PDMS & $\begin{array}{l}\text { HOFI X1, ROKIT } \\
\text { 3DISON, Custom } \\
\text { Printer }\end{array}$ & $\begin{array}{c}\text { Creating complex microfluidic } \\
\text { features like unconventional cross } \\
\text { sections or overhangs, optically } \\
\text { transparent }\end{array}$ & $\begin{array}{l}\text { Single line particle focusing, }{ }^{95} \text { facile } \\
\text { fabrication of complex systems }{ }^{96,97}\end{array}$ \\
\hline & PLA & $\begin{array}{l}\text { Sethi3D S3, BCN3D } \\
\text { Sigma, Printech } 200\end{array}$ & $\begin{array}{l}\text { Biocompatible, compatible with } \\
\text { various solvents, strong bonding with } \\
\text { other materials }\end{array}$ & $\begin{array}{c}\text { Creation of hybrid devices, }{ }^{147,148,153,155} \\
\text { double emulsion generation and } \\
\text { micromixing, }{ }^{148} \text { nanoparticle } \\
\text { synthesis }{ }^{153}\end{array}$ \\
\hline & Silicone & Custom Printer & $\begin{array}{l}\text { Biocompatible, flexible enough to } \\
\text { retain microchannel integrity after } \\
\text { bending of device }\end{array}$ & Microfluidic organ biopsy ${ }^{156}$ \\
\hline & Thermoplastic PU & Prusa i3 MK3 & $\begin{array}{l}\text { Biocompatible, prints small channels, } \\
\text { optical transparency }\end{array}$ & $\begin{array}{l}\text { Microchannel fabrication with } \\
\text { dimensions }<100 \mu \mathrm{m}^{149}\end{array}$ \\
\hline \multirow[t]{3}{*}{ SLA } & Clear Resin & $\begin{array}{l}\text { Formlabs Form 2, } \\
\text { Form } 1+\end{array}$ & $\begin{array}{l}\text { Biocompatible, optically clear, easy to } \\
\text { clean }\end{array}$ & Bioluminescence detection $^{159}$ \\
\hline & PDMS & Custom Printer & Biocompatible, PDMS characteristics & Characterizing printed PDMS ${ }^{157}$ \\
\hline & PEGDA & Custom Printer & $\begin{array}{l}\text { Biocompatible, truly microfluidic } \\
\text { channels, transparent }\end{array}$ & $\begin{array}{l}\text { Component formation within a device, } \\
161,165 \text { microchip electrophoresis }{ }^{163}\end{array}$ \\
\hline \multirow[t]{4}{*}{ PJ } & PDMS & DMP-3000 & $\begin{array}{l}\text { Unconventional cross sections and } \\
\text { overhang features, optically } \\
\text { transparent }\end{array}$ & $\begin{array}{l}\text { Flexible microfluidic systems with } \\
\text { electronic components }{ }^{98}\end{array}$ \\
\hline & VeroClear & $\begin{array}{l}\text { Objet } 350 \text { Connex } 3 \text {, } \\
\text { Stratasys } \mathbf{J} 750\end{array}$ & $\begin{array}{l}\text { Biocompatible, optical transparency, } \\
\text { complex channel geometries }\end{array}$ & $\begin{array}{l}\text { Simple support material removal, } \\
\text { double emulsion generation }\end{array}$ \\
\hline & VisiJet M2R-CL & ProJet MJP 2500 & $\begin{array}{l}\text { Biocompatible, optical transparency, } \\
\text { flexibility }\end{array}$ & Micromixing devices ${ }^{167}$ \\
\hline & VisiJet M3 Crystal & ProJet 3510 & $\begin{array}{l}\text { Biocompatible, optical transparency, } \\
\text { low autofluorescence }\end{array}$ & Electrophoresis ${ }^{168,169}$ \\
\hline
\end{tabular}

